\title{
Nanoscale Pore Structure Characterization and Permeability of Mudrocks and Fine-Grained Sandstones in Coal Reservoirs by Scanning Electron Microscopy, Mercury Intrusion Porosimetry, and Low-Field Nuclear Magnetic Resonance
}

\author{
Na Zhang $\left(\mathbb{D},{ }^{1,2}\right.$ Fangfang Zhao, ${ }^{1,2}$ Pingye Guo $\mathbb{D}^{1,2}$ Jiabin Li, ${ }^{2}$ Weili Gong, \\ Zhibiao Guo, ${ }^{1,2}$ and Xiaoming Sun (iD $^{1,2}$ \\ ${ }^{1}$ State Key Laboratory for Geomechanics and Deep Underground Engineering, Beijing 100083, China \\ ${ }^{2}$ School of Mechanics, Architecture and Civil Engineering, China University of Mining and Technology, Beijing 100083, China
}

Correspondence should be addressed to Na Zhang; zhangn@cumtb.edu.cn and Pingye Guo; guopingye@foxmail.com

Received 2 November 2017; Revised 23 March 2018; Accepted 8 April 2018; Published 28 May 2018

Academic Editor: Christophe Renac

Copyright (C) $2018 \mathrm{Na}$ Zhang et al. This is an open access article distributed under the Creative Commons Attribution License, which permits unrestricted use, distribution, and reproduction in any medium, provided the original work is properly cited.

\begin{abstract}
Porosity and permeability of two typical sedimentary rocks in coal bearing strata of underground coal mines in China, i.e., mudrocks and fine-grained sandstones, were comprehensively investigated by multiple experimental methods. Measured porosity averages of the helium gas porosity $\left(\varphi_{g}\right)$, MIP porosity $\left(\varphi_{\text {MIP }}\right)$, water porosity $\left(\varphi_{w}\right)$, and NMR porosity $\left(\varphi_{\mathrm{NMR}}\right)$ of the twelve investigated rock samples range from 1.78 to $16.50 \%$ and the measured gas permeabilities $\left(K_{g}\right)$ range from 0.0003 to $2.4133 \mathrm{mD}$. Meanwhile, pore types, pore morphologies, and pore size distributions (PSD) were determined by focused ion beam scanning electron microscopy (FIB-SEM), mercury intrusion porosimetry (MIP), and low-field nuclear magnetic resonance (NMR). FIB-SEM image analyses showed that the mineral matrix pores including interparticle (interP) and intraparticle (intraP) pores with varied morphologies are the dominant pore types of the investigated rock samples while very few organic matter $(\mathrm{OM})$ pores were observed. Results of the MIP and the full water-saturated NMR measurements showed that the PSD curves of the mudrock samples mostly present a unimodal pattern and nanopores with pore diameter less than $0.1 \mu \mathrm{m}$ are their predominant pore type, while the PSD curves of the fine-grained sandstone samples are featured by a bimodal distribution. Furthermore, comparison of the full water-saturated and irreducible-water-saturated NMR measurements indicated that pores in the mudrocks are solely adsorption pores (normally pore size $<0.1 \mu \mathrm{m}$ ) whereas apart from a fraction of adsorption pores, a large part of the pores in the sandstone sample with relatively high porosity are seepage pores (normally pore size $>0.1 \mu \mathrm{m}$ ). Moreover, the PSD curves of NMR quantitatively converted from the NMR $T_{2}$ spectra by $T_{2} P_{c}$ and weighted arithmetic mean (WAM) methods are in good agreement with the PSD curves of MIP. Finally, the applicability of three classic permeability estimation models based on MIP and NMR data to the investigated rock samples was evaluated.
\end{abstract}

\section{Introduction}

In China, coal reservoirs of most coalfields are rich in gas which frequently induces serious gas explosion disasters during coal mining practices. Among many controlling parameters, permeability is the key factor governing the fluid transport in geological media and thus has the most important impact on the migration and recovery process of coalbed methane [1-4]. Moreover, pore structure characteristics, for example, pore types, pore morphology, pore size distribution
(PSD), and porosity, are closely related to the permeability of reservoir rocks [5-7]. Therefore, investigation on the pore microstructural characteristics and permeability of typical coal reservoir rocks is of great significance to ensure the safe and efficient exploitation of coal and coalbed methane.

So far, researchers have conducted investigations concerning the geophysical characteristics of sandstone [8-12] and carbonate reservoirs [13-15]. Increasing efforts have also been devoted to the study of the pore structure and permeability of low permeable and fine-grained sedimentary 
reservoirs such as shale and tight sandstone $[16,17]$. However, in addition to its great importance in tight oil and gas exploration, the importance of the studies on pore structure and permeability of mudrocks and fine-grained sandstones for the exploitation of coal and coalbed methane resources cannot be ignored [18].

At present, there are a series of experimental methods such as scanning electron microscopy (SEM) [19-31], mercury intrusion porosimetry (MIP) [5, 32-36], and low-field nuclear magnetic resonance (NMR) [35-40] which have been widely applied for qualitative and quantitative determination of pore structure characteristics of different types of reservoir rocks. Among them, high resolution SEM-based imaging techniques, for example, field emission SEM (FE-SEM) [19, 20, 22-25], broad ion beam SEM (BIB-SEM) [21, 27, 29], and focused ion beam SEM (FIB-SEM) [26-31, 41], are commonly used in the field of visualized characterization of nanoscale pore systems of tight reservoir rocks such as gas shales and fine-grained sandstones due to their high resolution imaging advantages. For example, nanoscale pore structure characteristics of the organic-rich Wufeng-Longmaxi shale and the Lower Cambrian Niutitang shale were investigated by Yang et al. [19] and Sun et al. [24] using FE-SEM. Meanwhile, pore types and lithologic compositions within the mudrocks (mudstones and shales) were analyzed by Loucks et al. [25] based on a series of SEM images obtained from two types of FE-SEMs. Klaver et al. [21] studied the pore space morphology in two early mature samples of Posidonia shale using BIB-SEM. The 2D and 3D nanopore characteristics of the Longmaxi gas shales were investigated based on FIB-SEM devices by Jiao et al. [30] and Zhou et al. [31].

Unlike SEM techniques, MIP and NMR are both indirect approaches of pore structure characterization which can provide quantitative and more comprehensive pore information including pore distribution, porosity, and permeability. Specifically, MIP is a well-established technique based on capillary pressure measurement and it has been widely adopted for pore structure characterization of various kinds of porous media [32, 33]. MIP has many advantages such as wide measurable pore-throat sizes (normally between $3 \mathrm{~nm}$ and $\sim 500 \mu \mathrm{m})$, easy-operating, and time-saving. Therefore, many researchers have conducted a lot of researches on the pore structure characteristics of different types of reservoir rocks based on MIP method [5, 6, 32-36, 41, 42]. For example, Zhang et al. [5] studied pore structure characteristics and permeability of seven types of deep sedimentary rocks (i.e., mudstone, sandy mudstone, siltstone, fine sandstone, medium sandstones, coarse sandstone, and conglomerate) based on MIP measurement data. Yang et al. [41] investigated the characteristics of pore systems in organic-rich Wufeng and Longmaxi shales by using a few of complementary methods including MIP. Lai and Wang [42] analyzed the pore fractal characteristics of the tight gas sandstones using highpressure mercury intrusion techniques.

On the other hand, NMR is also a very powerful and distinctive pore characterization approach. It features as a fast, convenient, and nondestructive tool for characterizing complex porous media, particularly the petroleum reservoir rocks such as carbonate and sandstone [37, 38, 43]. Besides pore distribution information, NMR can also distinguish adsorption pores and seepage pores based on $T_{2}$ distributions at both the full water-saturated and irreducible-watersaturated conditions. Therefore, its practical application in the geophysical field has been getting more and more attention from petrophysicists and petroleum engineers [40, 44]. Recently, there are also some researches which applied NMR to the investigation of the pore structure and pore related parameters of coals $[35,38]$.

Except the above-mentioned pore structure determination methods, there are still many other sophisticated techniques, for example, the transmission electron microscopy (TEM) [4], X-ray computed tomography (CT) [45-49], nitrogen gas adsorption $[19,24,50]$, and small angle neutron scattering (SANS) [51-53], but they will not be discussed in this work. It is worth mentioning that multiple complementary methods are more and more often combinedly employed by researchers in order to acquire a multiscale and more comprehensive in-depth information of the pore structure of various types of reservoir rocks $[19,27,28]$.

The present work is aimed at investigating the nanoscale pore structure characteristics as well as porosity and permeability of the mudrock and fine-grained sandstone which are the most typical rock types in coal reservoirs of China by using combined methods of FIB-SEM, MIP, and NMR. Ten mudrock samples and two fine-grained sandstone samples were collected from the coal bearing strata of two underground coal mines in China. Major pore types and pore morphologies were visually recognized based on the FIBSEM images. Pore distribution characteristics were analyzed based on the acquired MIP and NMR data. Adsorption and seepage pores were further differentiated based on NMR measurements. Meanwhile, two kinds of calibration methods were put forward to quantitatively calibrate NMR $T_{2}$ spectra and the calibrated NMR PSD curves were compared with those determined by MIP. Furthermore, the applicability of three representative permeability estimation models on the basis of MIP and NMR measurement data to our investigated rock samples was evaluated.

\section{Experimental Methods}

2.1. Rock Samples. Rock blocks of shale, mudstone, and finegrained sandstone were collected from the coal reservoirs of two underground coal mines in China including the Ningtiaota (NT) Coal Mine located in Yulin of Shanxi province and the Jiahe $(\mathrm{JH})$ Coal Mine located in Xuzhou of Jiangsu province. The coal bearing strata of the NT and JH coal mines where all the investigated rock samples were collected belong to Middle Jurassic and Upper Carboniferous, respectively. The rock blocks were processed into uniform size of $\Phi 25$ $\times 35 \mathrm{~mm}$ cylindrical cores in the laboratory. A total of 12 selected rock core samples were dried in a vacuum drying oven for about 4 hours at $105^{\circ} \mathrm{C}$ until their weights had little changes. Dried samples were then stored in desiccators until being used at subsequent permeability tests and pore structure measurements. Table 1 lists the basic petrographic characteristics of all the rock samples investigated in this study. 
TABLE 1: Petrographic characteristics of the rock samples investigated in this study.

\begin{tabular}{|c|c|c|c|}
\hline $\begin{array}{l}\text { Sample } \\
\text { number }\end{array}$ & Lithology & Macroscopic image* $^{*}$ & Petrographic characteristics \\
\hline $\mathrm{JH}-\mathrm{Y}$ & Shale & & Brown laminar shale \\
\hline $\mathrm{JH}-\mathrm{S}$ & Sandstone & & $\begin{array}{l}\text { Caesious sandstone with good } \\
\text { gradation and fine psephicity of } \\
\text { grains }\end{array}$ \\
\hline NT-Y1 & & & Dark grey laminated silty shale \\
\hline NT-Y2 & Shale & & Grey laminated silty shale \\
\hline NT-Y3 & & & Brown laminated silty shale \\
\hline NT-M1 & & & Gray massive mudstone \\
\hline NT-M2 & & & Gray massive mudstone \\
\hline NT-M3 & & & Yellow-gray massive mudstone \\
\hline & Mudstone & & \\
\hline NT-M4 & & & Gray massive mudstone \\
\hline NT-M5 & & & Dark gray massive mudstone \\
\hline NT-M6 & & & Gray massive mudstone \\
\hline NT-S & Sandstone & & $\begin{array}{c}\text { Grey white fine-grained } \\
\text { sandstone with good gradation of } \\
\text { detrital grains }\end{array}$ \\
\hline
\end{tabular}

*Scale bar for the macroscopic images: ${ }^{1 \mathrm{~cm}}$.

2.2. Geochemical Characterizations. Before all the tests, mineralogical compositions of the bulk rock samples and their clay fractions $(<2 \mu \mathrm{m})$ were determined by X-ray diffraction (XRD) measurements using a German Bruker D8 Discover $\mathrm{X}$-ray diffractometer and semiquantified by Jade ${ }^{\circledR} 6.0$ software according to the Chinese Oil and Gas Industry Standard
SY/T 5163-2010. Small fragments of the rock samples were crushed into powdered samples of less than 300 mesh and glass slides of the powdered samples (1-2 g) were prepared for X-ray diffraction analysis under the following working conditions: voltage of $40 \mathrm{kV}$, current of $30 \mathrm{~mA}$, and scanning angle ranging from $2^{\circ}$ to $70^{\circ}$ at a step of $0.02^{\circ}$. Before 
the XRD analyses of the clay minerals in the samples, the clay fractions were separated using the pretreatment method of sedimentation and decantation. Then, the percentage contents of various clay minerals in the sample were deduced semiquantitatively.

Meanwhile, the total organic carbon (TOC) contents were measured using a LECO CS-230 Carbon/Sulfur Determinator according to the Chinese Oil and Gas Industry Standard GB/T 19145-2003. Small chips of the rock samples were crushed into powdered samples ( $10 \mathrm{~g})$ of less than 100 mesh and carbonate constituents were removed through treatment in hydrochloric acid of $1.5 \mathrm{~mol} / \mathrm{L}$ under temperature of $60-80^{\circ} \mathrm{C}$ for more than 2 hours. The treated samples were then washed to neutral by distilled water and dried in an oven at temperature of $60-80^{\circ} \mathrm{C}$ before TOC contents were finally analyzed.

\subsection{Density, Porosity, and Permeability Measurements. The} density of all the dry rock core samples was determined according to their dry weights and bulk volume. Meanwhile, the helium porosity, water porosity, and gas permeability were measured, respectively, using the routine core analysis methods described by the PRC National Standard GB/T 29172-2012. The helium porosities $\left(\varphi_{q}\right)$ of all the investigated rock core samples were determined by helium porosimetry using a helium porosimeter based on Boyle's Law. The water porosities $\left(\varphi_{w}\right)$ of all the investigated rock core samples were measured through water saturation method. The gas permeability $\left(K_{q}\right)$ of all the rock core samples was determined using a gas permeability testing apparatus by flowing high purity nitrogen through the core samples. The apparatus was constituted by a series of components including gas cylinder, core holding unit, pressure gauge, filter, voltage regulator, galvanostat, and gas flow meter.

2.4. Focused Ion Beam Scanning Electron Microscopy (FIB$S E M)$. In order to observe the nanoscale microstructural pore features, that is, types, morphology, and distribution of nanopores, the nanoscale microscopic images of four selected samples (JH-Y, JH-S, NT-M2, and NT-Y3 in Table 1), which are the representative samples of $\mathrm{JH}$ Coal Mine and NT Coal Mine, were obtained using a FEI Nova NanoLab 200 FIB/SEM. The Nova NanoLab combines ultra-high resolution field emission scanning electron microscopy (SEM) and precise focused ion beam (FIB) etch and deposition. Resolution at $5 \mathrm{kV}$ (TLD-SE) is $2.0 \mathrm{~nm}$. Before FIB-SEM imaging, one chosen surface of each selected rock sample $(10 \mathrm{~mm}$ in width, $5 \mathrm{~mm}$ in height, and $15 \mathrm{~mm}$ in length) was polished by argon ion to create a smooth surface using a Hitachi Ion Milling System IM4000. The polished surface was coated with gold to form a conductive surface of $10 \mathrm{~nm}$ thickness. Finally, the argon ion polished rock samples were digitally imaged under through-the-lens detector (TLD) mode for detecting secondary electrons and backscattered electrons.

2.5. Mercury Intrusion Porosimetry (MIP). Pore structure characteristics such as pore size distribution and some other parameters including porosity, total pore volume/area, median pore diameter, average pore diameter, bulk density, and apparent density were all determined by MIP experiments using an AutoPore IV 9500 Porosimeter (Micrometrics, USA) according to the Chinese Oil and Gas Industry Standard SY/T 5346-2010. MIP tests were performed on the twelve prepared dry rock core samples $(\Phi 25 \times 35 \mathrm{~mm})$. During each MIP test, both low pressure and high-pressure analyses were performed. The lowest and highest pressures applied were approximately 0.5 and 60,000 psia which correspond to the largest and smallest pore-throat diameters of $365 \mu \mathrm{m}$ and $3 \mathrm{~nm}$, respectively.

2.6. Low-Field Nuclear Magnetic Resonance Measurements (NMR). The NMR measurements were successively conducted on all the rock core samples at the full water-saturated $\left(S_{w}\right)$ and irreducible-water-saturated $\left(S_{\mathrm{ir}}\right)$ condition using a RecCore-04 NMR sample analyzer manufactured by the China National Petroleum Corporation according to the Chinese Oil and Gas Industry Standard SY/T 6490-2014. The apparatus has a constant magnetic field strength of 1200 gauss and a resonance frequency of $3.84 \mathrm{MHz}$. All the NMR measurements were performed under room temperature of $\sim 25^{\circ} \mathrm{C}$ and the test parameters were set as follows: echo spacing for $0.5 \mathrm{~ms}$, waiting time for $3 \mathrm{~s}$, number of echo for 1024, and number of scan for 64. Based on $T_{2}$ distribution curves both at $S_{w}$ and $S_{\mathrm{ir}}$, features of pore size distributions and different pore types such as adsorption pores (normally pore size $<0.1 \mu \mathrm{m}$ ) and seepage pores (normally pore size $>$ $0.1 \mu \mathrm{m}$ ) were able to be recognized [38].

\section{Results}

3.1. TOC and Mineralogical Compositions. The TOC contents as well as the mineralogical compositions including clay minerals of all the investigated rock samples are listed in Table 2. It is shown that the TOC values distribute in a relative wide range from 0.03 (JH-S) to $10.81 \%(\mathrm{JH}-\mathrm{Y})$. Among all the samples, sandstone samples JH-S and NT-S have the lowest TOC values which are 0.03 and $0.06 \%$, respectively. Meanwhile, the TOC average values for sandstone, mudstone and shale sample groups are calculated as $0.05,1.04$, and $5.55 \%$. As we know, TOC value is a reflection of the richness of the organic matter contained in a sample. Thus, the results indicate that the investigated shale and mudstone samples generally contain much more organic matters than the finegrained sandstone samples. The fact that the organic matter is richer in the shale and mudstone samples than in the sandstone samples is closely associated with their distinct genesis. According to Rimmer et al. [54] and Zhao et al. [55], both the influx of terrigenous clastic and the redox environment play important roles in the enrichment of organic matter during diagenesis process. Because of the abundant clastic influx and the partial oxidation environment, the content of organic matter in sandstone is normally lower than in the mudrocks.

From Table 2, it is also found that the mineral components contained in all the shale, mudstone, and finegrained sandstone samples mainly include clay minerals, quartz, plagioclase, and potassium feldspar and most shale 
TABLE 2: Total organic carbon (TOC) contents and mineralogical compositions of the investigated rock samples.

\begin{tabular}{|c|c|c|c|c|c|c|c|c|c|c|c|c|}
\hline \multirow{2}{*}{ Sample number } & \multirow{2}{*}{ TOC (\%) } & \multicolumn{6}{|c|}{ Minerals (\%) } & \multicolumn{5}{|c|}{ Clay minerals (\%) } \\
\hline & & Clay minerals & Quartz & K-feldspar & Plagioclase & Pyrite & Siderite & Kaolinite & Chlorite & Illite & $I / S$ & $\% S$ \\
\hline JH-Y & 10.81 & 26 & 52 & 5 & 13 & & 4 & 60 & 10 & 7 & 23 & 25 \\
\hline JH-S & 0.03 & 30 & 43 & 8 & 19 & & & 77 & 9 & 4 & 10 & 30 \\
\hline NT-Y1 & 5.18 & 34 & 24 & 3 & 6 & & 33 & 55 & 23 & 11 & 11 & 25 \\
\hline NT-Y2 & 2.92 & 43 & 41 & 4 & 12 & & & 49 & 20 & 9 & 22 & 25 \\
\hline NT-Y3 & 3.29 & 25 & 16 & 1 & 2 & & 56 & 46 & 23 & 13 & 18 & 25 \\
\hline NT-M1 & 1.73 & 55 & 35 & 3 & 7 & & & 34 & 26 & 14 & 26 & 20 \\
\hline NT-M2 & 0.84 & 49 & 35 & 4 & 12 & & & 44 & 25 & 12 & 19 & 25 \\
\hline NT-M3 & 0.62 & 42 & 39 & 4 & 12 & & 3 & 45 & 26 & 10 & 19 & 25 \\
\hline NT-M4 & 0.73 & 50 & 38 & 3 & 9 & & & 39 & 25 & 13 & 23 & 25 \\
\hline NT-M5 & 1.08 & 47 & 37 & 4 & 12 & & & 45 & 23 & 13 & 19 & 25 \\
\hline NT-M6 & 1.21 & 44 & 41 & 3 & 12 & & & 44 & 25 & 12 & 19 & 25 \\
\hline NT-S & 0.06 & 12 & 54 & 11 & 17 & 6 & & 89 & 6 & 3 & 2 & 25 \\
\hline
\end{tabular}

Note. I/S represents regular illite/smectite mixed layer; $\% S$ represents the percent content of smectite in regular $I / S$.

TABLE 3: Density, permeability, and porosities of the investigated rock samples.

\begin{tabular}{lcccccccc}
\hline $\begin{array}{l}\text { Sample } \\
\text { number }\end{array}$ & $\begin{array}{c}\text { Density } \\
\left(\mathrm{g} / \mathrm{cm}^{3}\right)\end{array}$ & $\begin{array}{c}\text { Permeability } \\
\left(K_{g}\right)(\mathrm{mD})\end{array}$ & $\begin{array}{c}\text { He porosity } \\
\left(\varphi_{g}\right)(\%)\end{array}$ & $\begin{array}{c}\text { MIP porosity } \\
\left(\varphi_{\mathrm{MIP}}\right)(\%)\end{array}$ & $\begin{array}{c}\text { Water } \\
\text { porosity } \\
\left(\varphi_{w}\right)(\%)\end{array}$ & $\begin{array}{c}\text { NMR } \\
\text { porosity } \\
\left(\varphi_{\text {NMR }}\right)(\%)\end{array}$ & $\begin{array}{c}\text { Statistical parameters of porosity } \\
\left(\varphi_{\text {Avg }}\right)(\%)\end{array}$ \\
\hline JH-Y & 2.53 & 0.0003 & 1.40 & 1.86 & 1.70 & 2.15 & 1.78 & 0.31 \\
Standard \\
deviation \\
JH-S
\end{tabular}

samples also contain some siderite. In addition, clay minerals mainly include kaolinite, chlorite, illite, and illite/smectite mixed layers, and kaolinite is the dominant clay mineral component for all the samples. Furthermore, for the two samples collected from the Jiahe Coal Mine (JH-Y and JH$\mathrm{S})$, their mineral compositions are very similar. Specifically, their average contents of clay minerals and quartz are 28 and $48 \%$, respectively. For the other ten samples collected from the Ningtiaota Coal Mine, it is found that sandstone has the lowest clay mineral content $(12 \%)$ but the highest quartz content $(54 \%)$ whereas mudstone has the highest clay mineral content (48\%) and shale is in-between (34\%). Also, it is worth noting that the colors of the samples vary due to the differences in their mineral compositions as well as their organic matter contents. For example, the samples which contain siderite such as JH-Y, NT-Y1, NT-Y3, and NTM3 show different shades of brown. Meanwhile, the samples with relatively high TOC such as $\mathrm{JH}-\mathrm{Y}$ are much darker in color than the other samples. Generally, the variations of geochemical compositions including OM and different minerals among the three different types of rocks, that is, the shale, mudstone, and fine-grained sandstone, can be attributed to their different geological diagenesis. During the diagenetic process, there are many controlling factors such as the terrigenous clastic supply and the redox environment which govern the differentiated abundance of various kinds of organic and inorganic compositions in different types of rocks.

3.2. Permeability and Porosities. Table 3 lists the measured density and gas permeability $\left(K_{g}\right)$ of all the investigated samples through the laboratory experiments. It is shown that all the samples have extremely low permeability values ranging from 0.0003 to $0.0048 \mathrm{mD}$ except one sandstone sample NT-S with relatively high value of $2.4133 \mathrm{mD}$. Table 3 also lists the porosities of each sample determined by the 


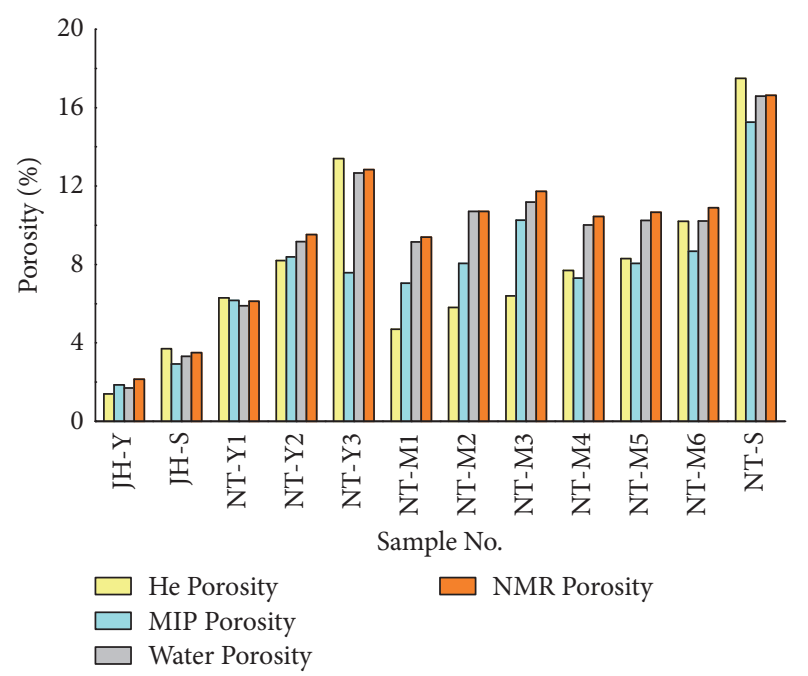

FIGURE 1: Distributions of the porosities determined by four different methods.

four different methods including helium gas porosity $\left(\varphi_{g}\right)$, MIP porosity $\left(\varphi_{\text {MIP }}\right)$, water porosity $\left(\varphi_{w}\right)$, and NMR porosity $\left(\varphi_{\mathrm{NMR}}\right)$. Distributions of the four measured porosities for all the samples are presented and compared in Figure 1. The NT samples have larger porosity than the $\mathrm{JH}$ samples. For $\mathrm{JH}$ samples, the porosities of the sandstone sample are larger than those of the mudrock sample which is also the case for the NT samples. Among all the samples, JH-Y has the lowest porosity while NT-S has the highest porosity and these two samples represent two distinct lithofacies, that is, a shale and a sandstone, respectively. Moreover, it is also found from Figure 1 that there are evident distinctions among the four different porosities of each sample. For a deeper analysis of the differences among the four porosities, their arithmetic average $\left(\varphi_{\mathrm{Avg}}\right)$, standard deviation (SD), and relative standard deviation (RSD) were calculated and listed in Table 3. It is found that the values of RSD range from $2.78 \%$ (NT-Y1) to $28.88 \%$ (NT-M1) which further indicates that marked discrepancies exist among the four porosity measurements. Meanwhile, one-to-one comparison analyses of the different groups of porosities suggest that NMR porosity generally agrees well with water porosity. The major reason for this discrepancies between $\varphi_{g}, \varphi_{\mathrm{MIP}}$, and $\varphi_{\mathrm{NMR}}$ may primarily owe to the possible high heterogeneity among the parallel samples which were used separately for the different porosity measurements. However, because $\varphi_{w}$ and $\varphi_{\mathrm{NMR}}$ measurements were performed on the same parallel sample, there is a good agreement between the two porosities. Furthermore, correlation analyses between the four different porosities and the measured permeability $\left(K_{g}\right)$ for the mudrock sample group collected from the NT coal mine suggested that the water porosity $\left(\varphi_{w}\right)$ and NMR porosity $\left(\varphi_{\mathrm{NMR}}\right)$ are much more positively correlated with the permeability $K_{g}$ than the He porosity $\left(\varphi_{g}\right)$ and MIP porosity $\left(\varphi_{\text {MIP }}\right)$.

3.3. Types and Morphologies of Pores (FIB-SEM). Nanoscale microscopic FIB-SEM images of the four selected rock samples as shown in Figures $2-5$ were acquired by the FIB-SEM measurements and analyzed comprehensively to disclose the predominant types and morphologies of pores existing in the investigated samples. Generally, it is found that the development of the pore systems in the selected samples is all relatively poor especially in tight samples like JH-Y and JH-S. Based on pore classification proposed by Loucks et al. [25], pore systems of mudrock are classified into matrix pore system and natural fracture. Matrix pore system is composed of two major types of pores: mineral matrix pores (pores associated with the mineral matrix) and OM pores (pores associated with organic matter $(\mathrm{OM})$ ) while mineral matrix pores (pores between or within mineral particles) mainly consist of two different types of pores, that is, interparticle (interP) pores and intraparticle (intraP) pores. Therefore, according to the pore system classifications of mudrocks and sandstones introduced by Loucks and Pittman $[23,25,56]$, the pore systems of the four selected samples were analyzed and classified. In general, mineral matrix pores associated with nonclay minerals (such as quartz, feldspar, and siderite) and clay minerals (such as kaolinite, chlorite, and illite) were all observed in the samples. Different forms of the interP and intraP pores found in the selected samples can be observed in Figures 2-5. Through careful observation, it can be seen that the geometric appearance of the recorded mineral matrix pores is very diversified and appears as varied shapes such as circular pores, irregular polygonal pores, narrow microcracks, and other forms. Overall, the pore systems of the samples are dominated by mineral matrix pores and only very few OM pores were observed.

\subsection{Pore Structure Characteristics Determined by MIP}

3.4.1. Pore Structure Parameters. Pore structure characteristics such as pore amount and pore size can be quantitatively described using a set of parameters measured by MIP experiments. Pore structure parameters including porosity, total pore volume, total pore area, median pore diameter, average pore diameter, bulk density, and apparent density of all the investigated samples obtained from MIP are listed in Table 4. Results have shown that the total pore volumes of the samples vary from 0.007 (JH-Y) to $0.069 \mathrm{~mL} / \mathrm{g}$ (NT-S) and their porosities are all below $16 \%$. Through comparison of the MIP parameters among the different lithologic groups (Figure 6), it is found that, for $\mathrm{JH}$ samples, the porosity, total pore volume, and median pore diameter of the sandstone sample $\mathrm{JH}-\mathrm{S}$ are all higher than the shale sample JH-Y. Meanwhile, for NT samples, there are also remarkable differences in those three parameters existing between the mudrock and the sandstone lithofacies.

3.4.2. Pore Size Distributions (PSD). The PSD curves (porethroat diameter versus $d V / \operatorname{dog} D$ pore volume) of shale, mudstone and sandstone samples were plotted in Figure 7 based on the MIP experimental data. It is indicated that the PSD curves of the shale and mudstone samples are all characterized by a single-peak distribution, and the pore size range is mostly distributed between $0.003-0.1 \mu \mathrm{m}$. According to the pore size classification scheme of mudrocks proposed 


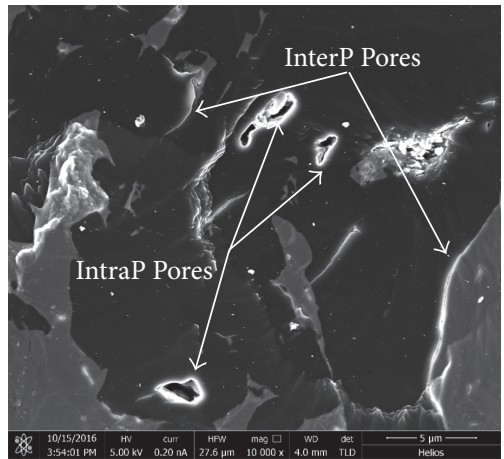

(a)

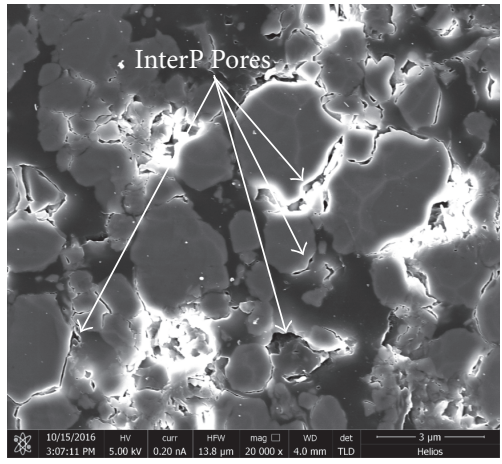

(d)

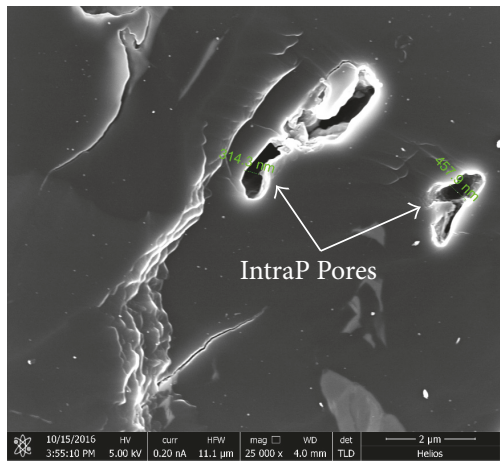

(g)

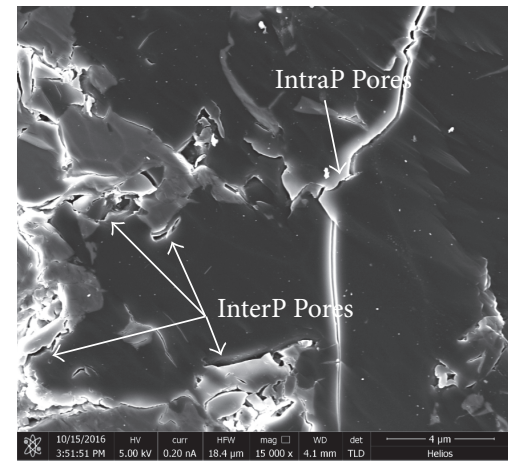

(b)

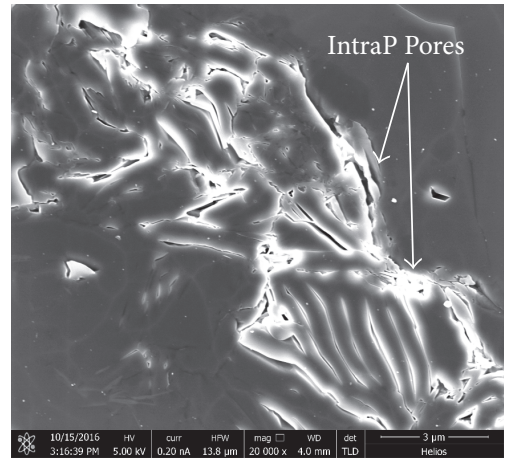

(e)

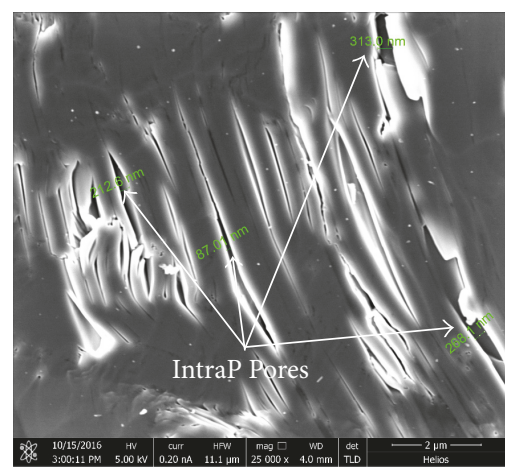

(h)

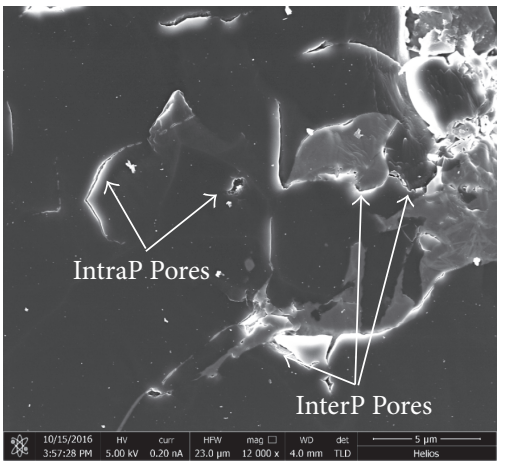

(c)

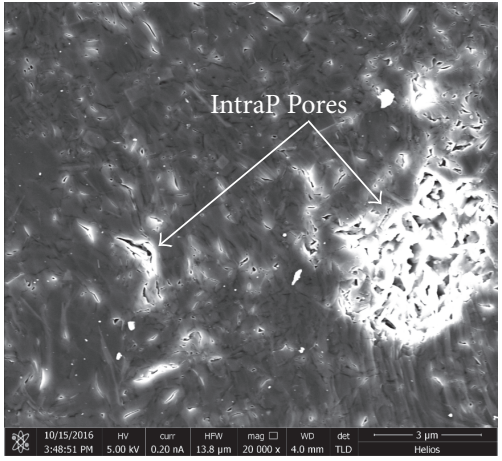

(f)

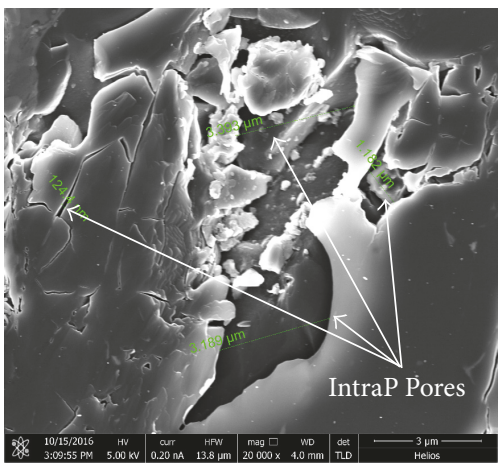

(i)

FIGURE 2: The FIB-SEM images of sample JH-Y $\left(\varphi_{\text {Avg }}=1.78 \% ; K_{g}=0.0003 \mathrm{mD}\right)$.

TABle 4: Parameters of pore-system structure measured by MIP.

\begin{tabular}{|c|c|c|c|c|c|c|c|}
\hline $\begin{array}{l}\text { Sample } \\
\text { number }\end{array}$ & $\begin{array}{c}\text { Porosity } \\
(\%)\end{array}$ & $\begin{array}{c}\text { Total pore } \\
\text { volume }(\mathrm{mL} / \mathrm{g})\end{array}$ & $\begin{array}{c}\text { Total pore area } \\
\left(\mathrm{m}^{2} / \mathrm{g}\right)\end{array}$ & $\begin{array}{c}\text { Median pore } \\
\text { diameter }(\mathrm{nm})\end{array}$ & $\begin{array}{l}\text { Average pore } \\
\text { diameter }(\mathrm{nm})\end{array}$ & $\begin{array}{l}\text { Bulk density } \\
(\mathrm{g} / \mathrm{mL})\end{array}$ & $\begin{array}{l}\text { Apparent (skeletal) } \\
\text { density }(\mathrm{g} / \mathrm{mL})\end{array}$ \\
\hline $\mathrm{JH}-\mathrm{Y}$ & 1.86 & 0.007 & 0.83 & 6.90 & 35.50 & 2.52 & 2.57 \\
\hline JH-S & 2.92 & 0.012 & 1.61 & 8.60 & 28.60 & 2.53 & 2.61 \\
\hline NT-Y1 & 6.16 & 0.023 & 5.65 & 11.40 & 16.10 & 2.71 & 2.89 \\
\hline NT-Y2 & 8.38 & 0.036 & 6.68 & 14.00 & 21.30 & 2.36 & 2.58 \\
\hline NT-Y3 & 7.58 & 0.032 & 12.17 & 6.70 & 10.30 & 2.41 & 2.61 \\
\hline NT-M1 & 7.05 & 0.029 & 11.62 & 6.70 & 10.00 & 2.42 & 2.61 \\
\hline NT-M2 & 8.06 & 0.033 & 10.12 & 9.85 & 13.20 & 2.44 & 2.65 \\
\hline NT-M3 & 10.26 & 0.043 & 11.10 & 11.90 & 15.60 & 2.37 & 2.64 \\
\hline NT-M4 & 7.30 & 0.030 & 10.36 & 8.10 & 11.60 & 2.43 & 2.62 \\
\hline NT-M5 & 8.05 & 0.034 & 9.75 & 10.30 & 13.70 & 2.40 & 2.61 \\
\hline NT-M6 & 8.68 & 0.036 & 11.27 & 9.30 & 12.80 & 2.41 & 2.64 \\
\hline NT-S & 15.26 & 0.069 & 1.20 & 64.00 & 230.40 & 2.21 & 2.61 \\
\hline
\end{tabular}




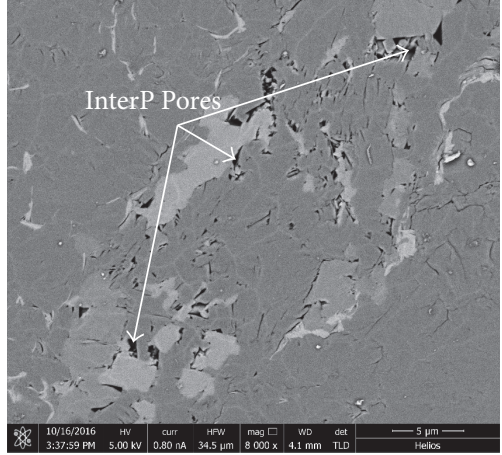

(a)

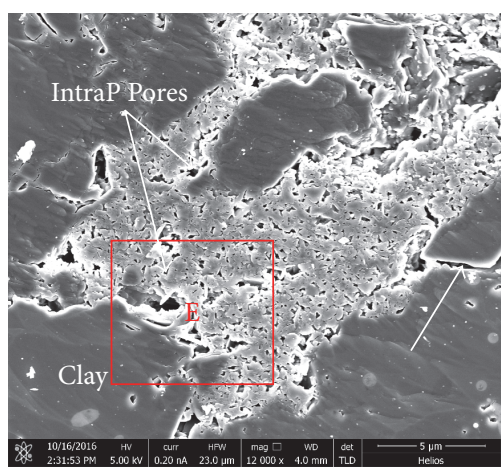

(d)

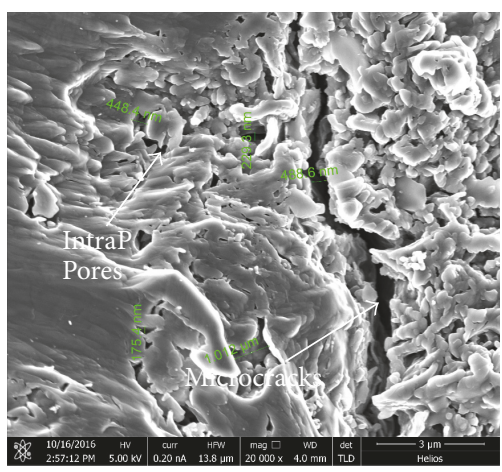

(g)

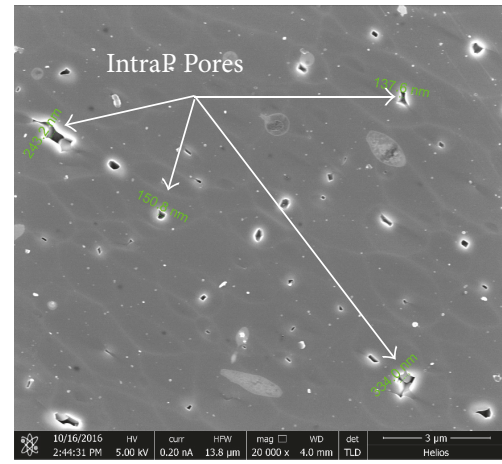

(b)

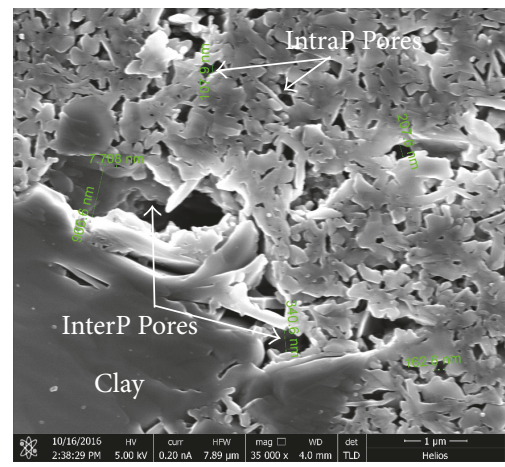

(e)

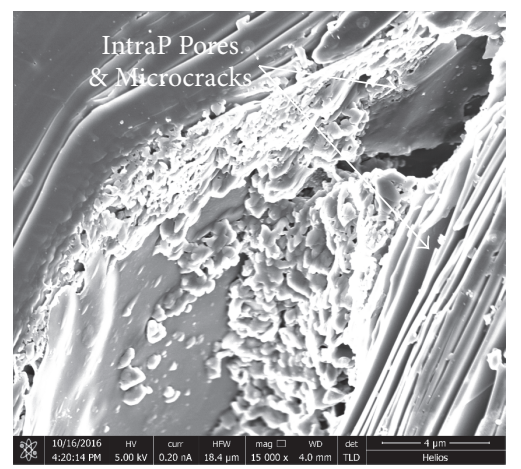

(h)

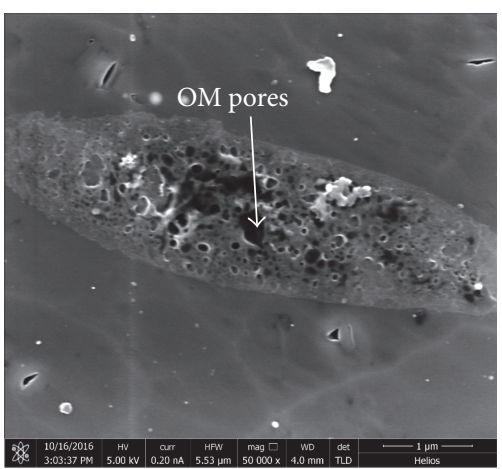

(c)

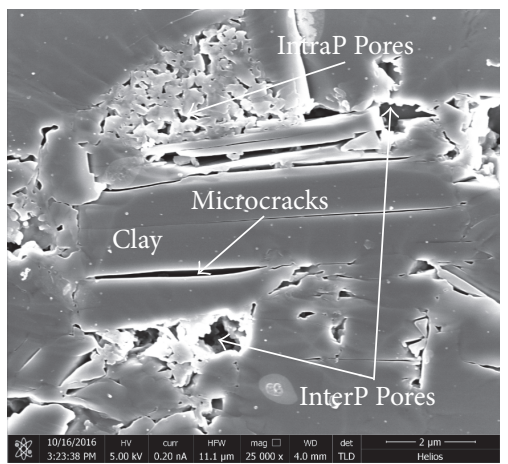

(f)

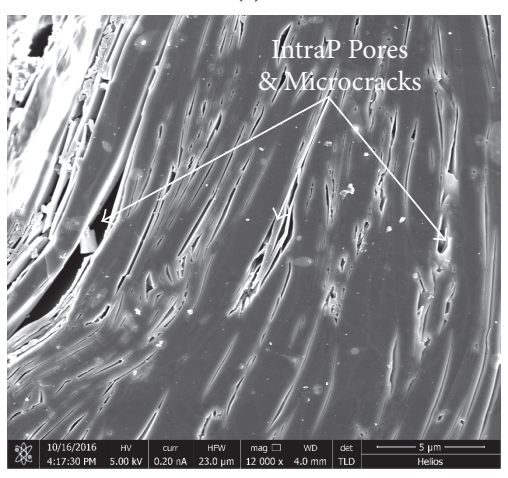

(i)

Figure 3: The FIB-SEM images of sample JH-S $\left(\varphi_{\text {Avg }}=3.36 \% ; K_{g}=0.0046 \mathrm{mD}\right)$.

by Loucks, et al. [25], the dominant pores in our investigated mudrock samples are mostly nanopores $(1 \mathrm{~nm} \leq d<1 \mu \mathrm{m})$ concentrated near the pore size of $0.01 \mu \mathrm{m}$. Furthermore, it is observed that the PSD curves of the two sandstone samples $\mathrm{JH}-\mathrm{S}$ and NT-S have double peaks. For sample JH-S, the two peaks are distributed in the ranges of $0.003-0.05 \mu \mathrm{m}$ and $0.05-0.5 \mu \mathrm{m}$ which all belong to the nanopore class, while for sample of NT-S the two peaks are distributed in the ranges of $0.01-1 \mu \mathrm{m}$ and $1-10 \mu \mathrm{m}$ which belong to the nanopore and micropore classes, respectively.

\subsection{Pore Structure Characteristics Determined by NMR Measurements}

3.5.1. NMR $T_{2}$ Spectra. Transverse relaxation time $\left(T_{2}\right)$ distribution curves (also called $T_{2}$ spectra) of all the full water-saturated and irreducible-water-saturated samples were plotted based on the NMR test data (see Appendix A). According to the basic principle of the NMR measurement [44], it is known that there is a positive correlation between $T_{2}$ and pore size, that is, shorter relaxation time corresponding to smaller pore size and longer relaxation time corresponding to larger pore size. Consequently, the measured $T_{2}$ distribution is a reflection of the PSD of the rock sample. $T_{2}$ spectra of the full water-saturated shale, mudstone, and fine-grained sandstone samples which can reflect the full spectrum pore size distribution pattern of each rock type are presented in Figure 8. It can be observed that, for both the shale and mudstone samples, their NMR $T_{2}$ spectra are characterized by a unimodal pattern with one major peak distributed in the range of 0.1 to $10 \mathrm{~ms}$, whereas for the sandstone sample NT-S, it is a bimodal distribution 


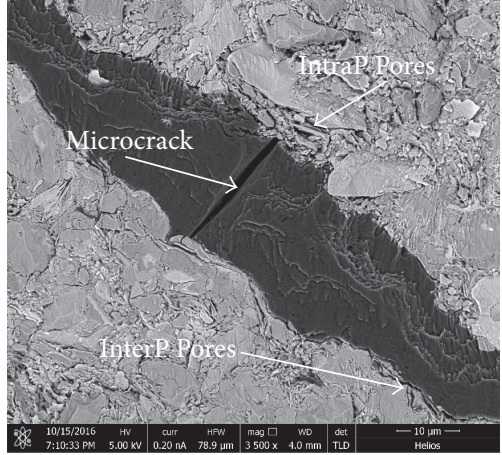

(a)

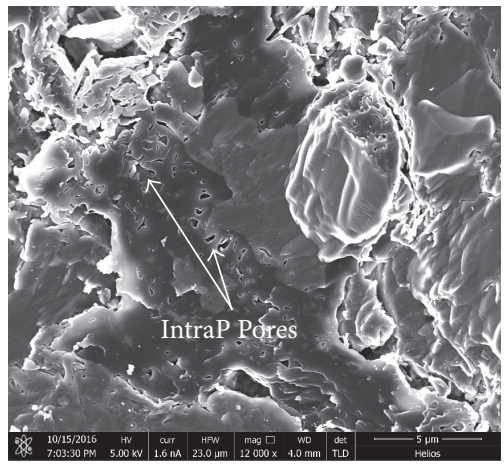

(d)

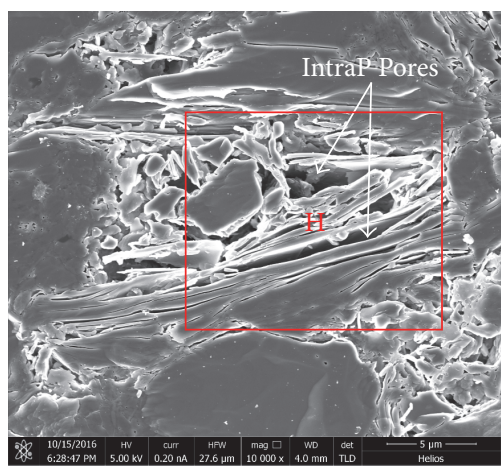

(g)

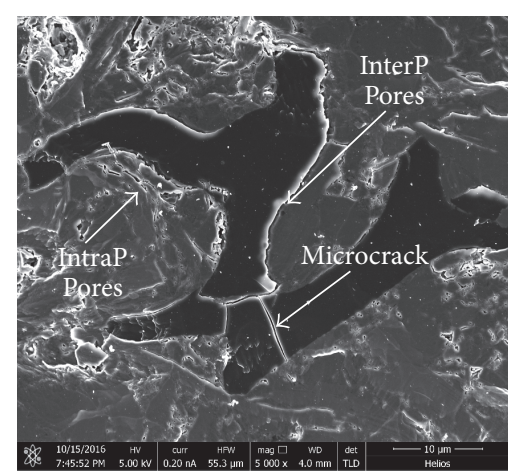

(b)

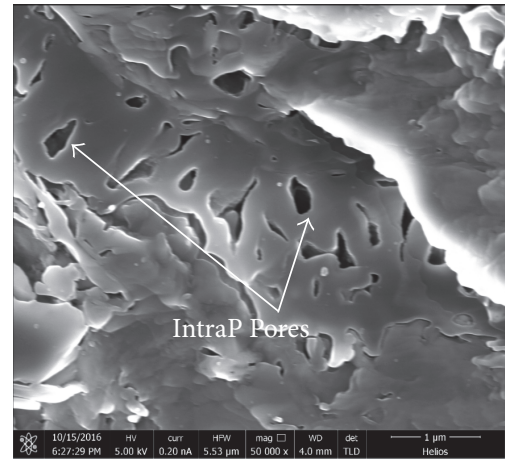

(e)

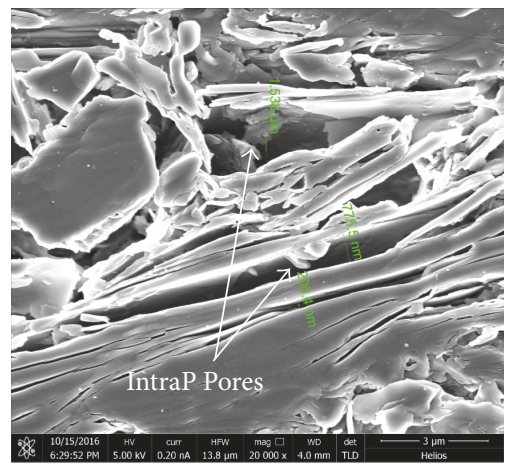

(h)

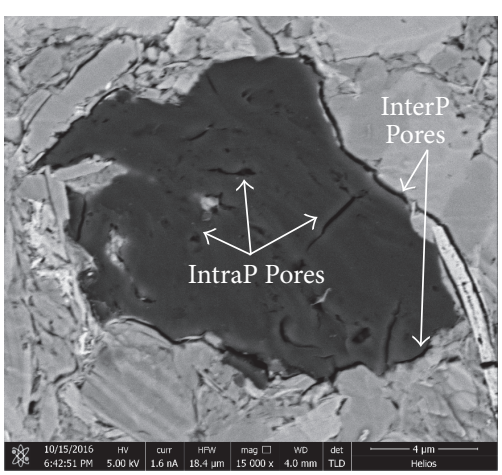

(c)

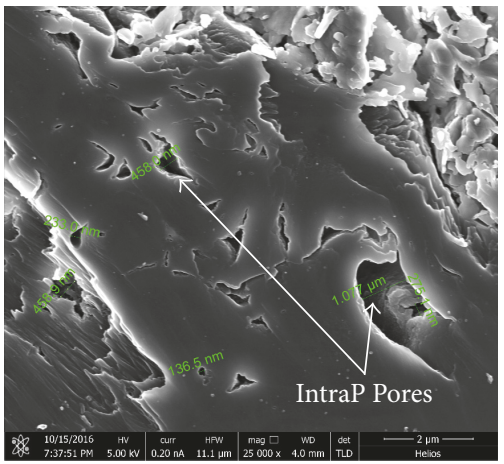

(f)

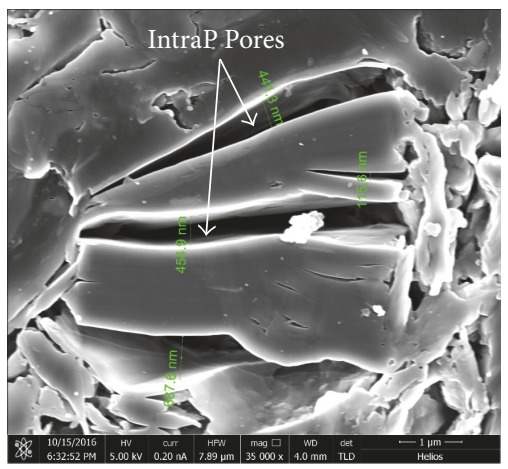

(i)

FIGURE 4: The FIB-SEM images of sample NT-M2 $\left(\varphi_{\text {Avg }}=8.82 \% ; K_{g}=0.0048 \mathrm{mD}\right)$.

with a major peak distributed in the range of 5 to $1000 \mathrm{~ms}$ and a minor peak in the range of 0.5 to $5 \mathrm{~ms}$. Overall, the PSD features of the investigated mudrock and fine-grained sandstone samples found by NMR agree well with those observed by MIP as described in the previous section.

3.5.2. Adsorption and Seepage Pores. Quantitatively partitioning of adsorption pore and seepage pore is of great importance for reservoir quality assessment. By definition, adsorption pores refer to those pores in which water cannot be drained out through centrifuging while seepage pores represent those pores in which water can flow freely and can be centrifuged easily under certain pressures. Usually, pore size of adsorption pores is smaller than $0.1 \mu \mathrm{m}$ while pore size of seepage pores is bigger than $0.1 \mu \mathrm{m}$ [38]. In adsorption pores the water is strongly confined to the pore walls due to the effects of electrostatic forces and capillary forces. The quantitative division of distribution characteristics of the adsorption pores of the investigated samples are reflected by the $T_{2}$ distribution curves of the irreducible-water-saturated samples (red solid line in Figure 11). It can be seen from Figure 11 that there is little difference between the adsorption pore distribution and the full spectrum pore distribution (black solid line in Figure 11) for all the ten investigated mudrock samples and one very tight sandstone sample $\mathrm{JH}$ $\mathrm{S}$ which has an extremely low NMR porosity of $3.50 \%$. However, a significant difference is observed between the distribution curves of adsorption pore and full spectrum pore for the sandstone sample NT-S which has a relatively high NMR porosity of $16.63 \%$. The $T_{2}$ spectra of the adsorption 


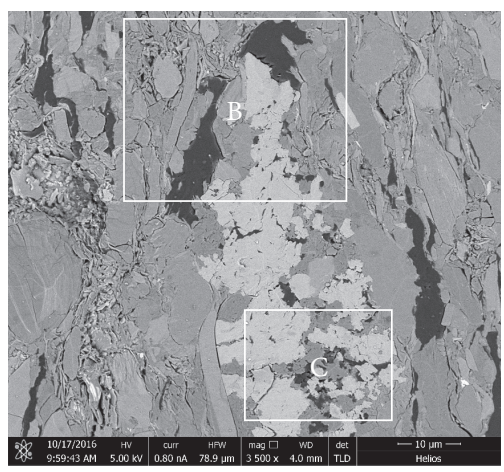

(a)

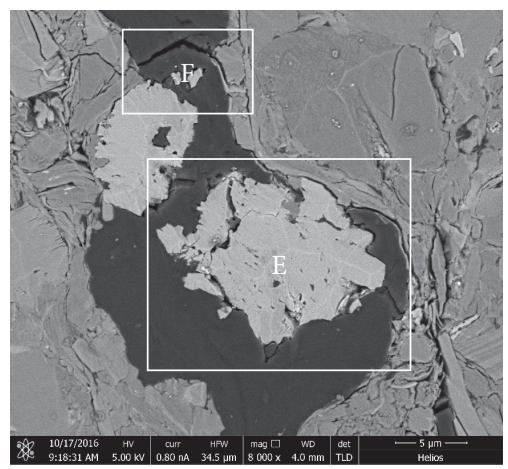

(d)

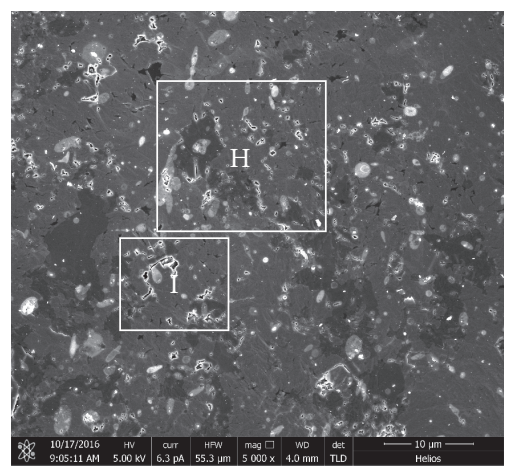

(g)

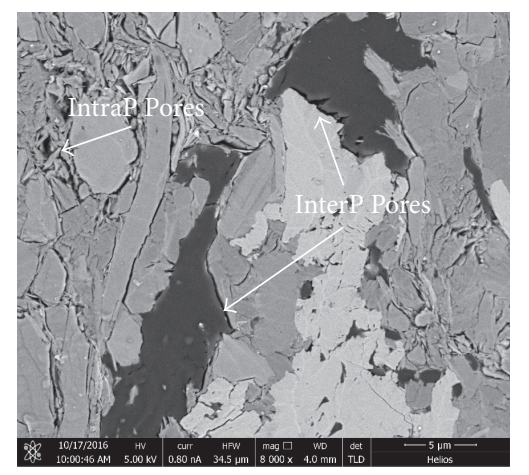

(b)

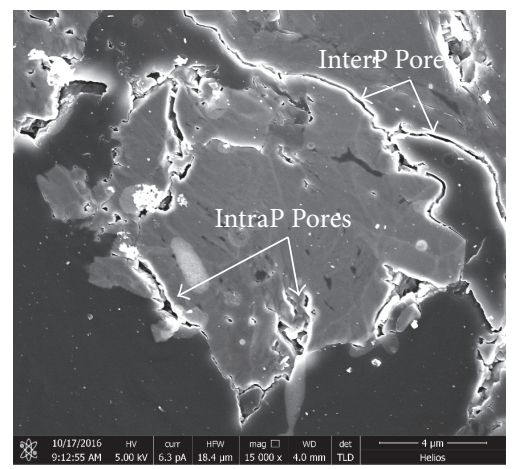

(e)

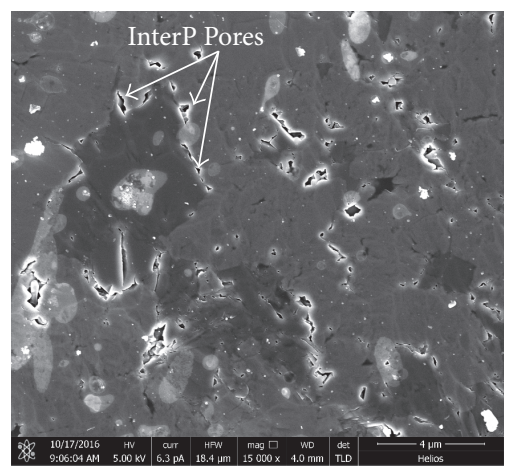

(h)

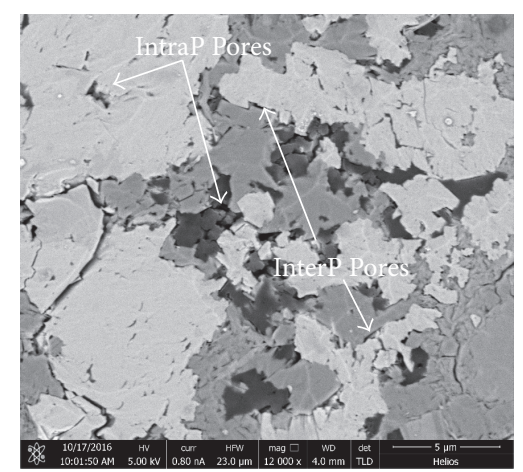

(c)

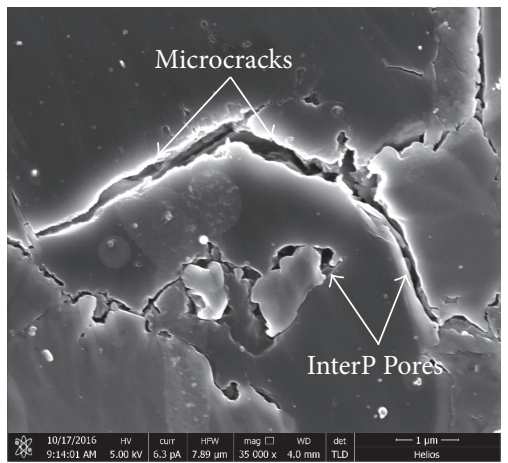

(f)

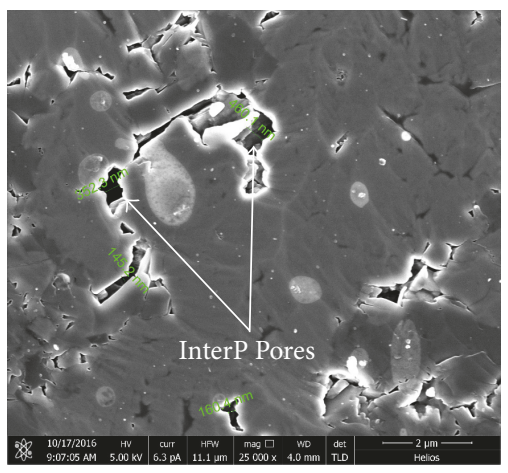

(i)

FIGURE 5: The FIB-SEM images of sample NT-Y3 $\left(\varphi_{\text {Avg }}=11.62 \% ; K_{g}=0.0028 \mathrm{mD}\right)$.
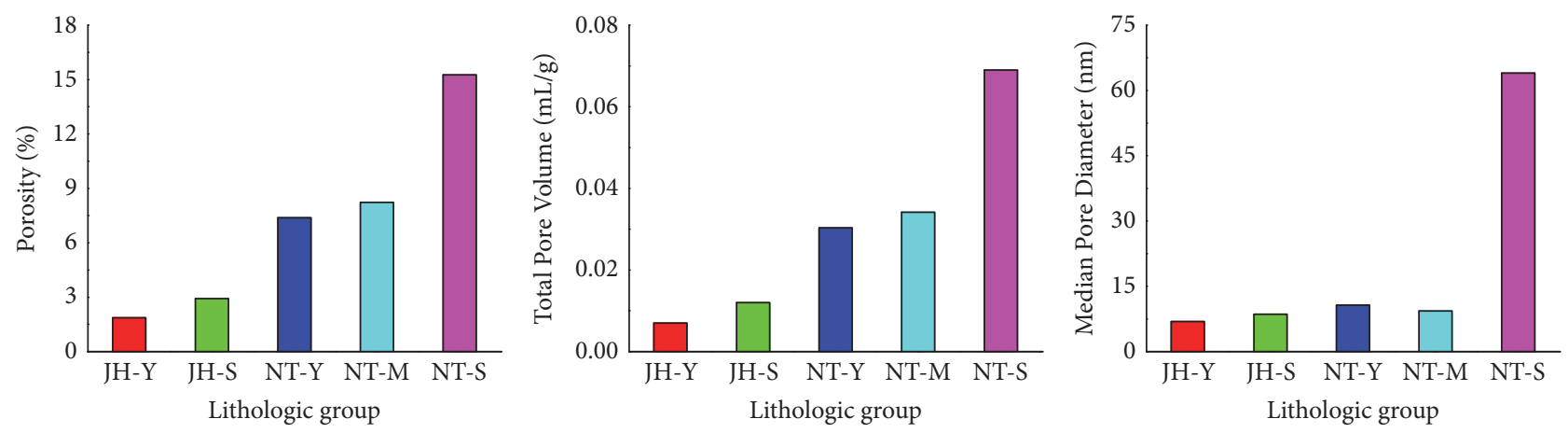

FIGURE 6: Comparison of MIP porosity, total pore volume, and median pore diameter averages among different lithologic groups of JH and NT coal mines (JH-Y: shale of JH; JH-S: sandstone of JH; NT-Y: shale of NT; NT-M: mudstone of NT; NT-S: sandstone of NT). 


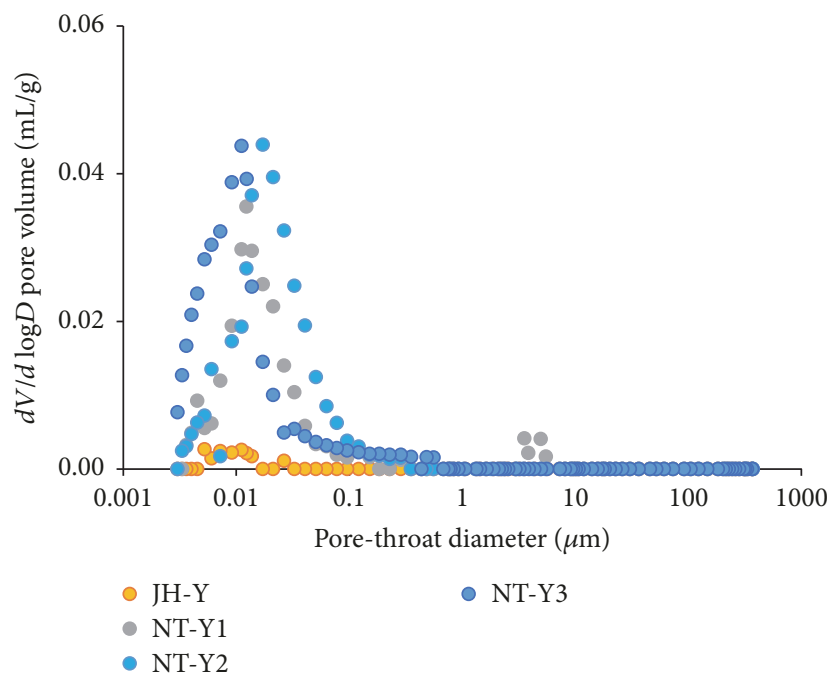

(a) Shale

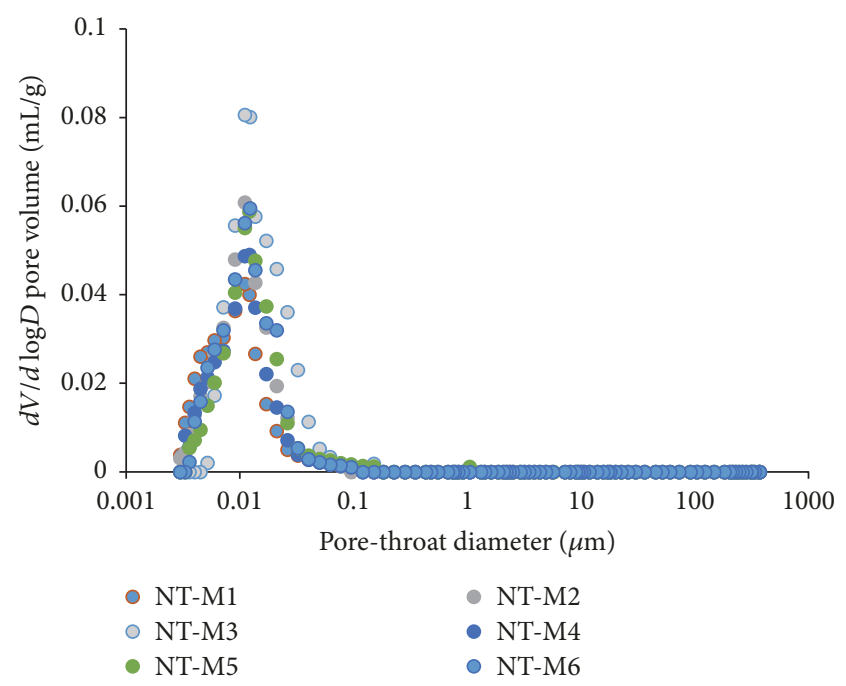

(b) Mudstone

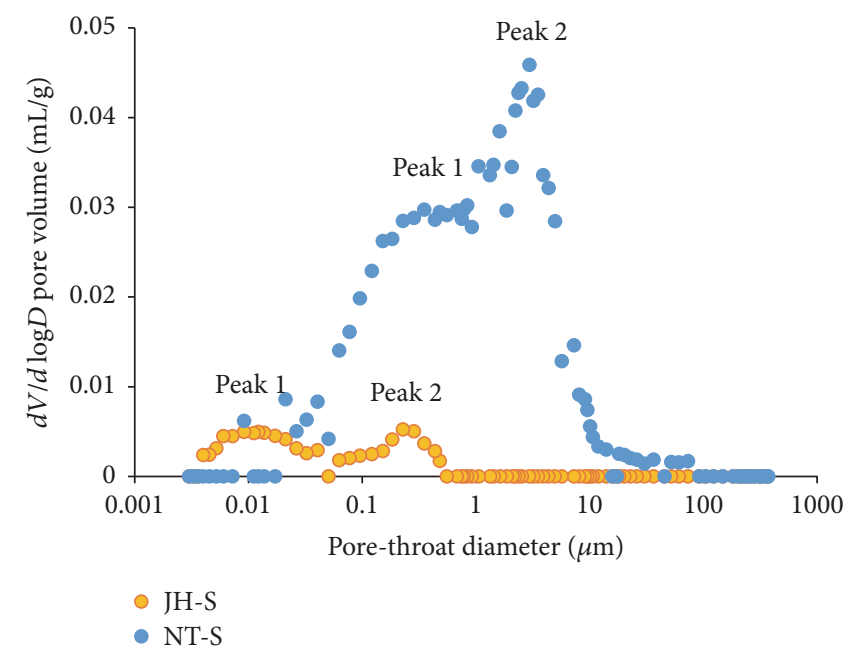

(c) Sandstone

FIGURE 7: Pore size distribution curves of the investigated samples obtained from the MIP measurements.

pore of NT-S are remarkably narrower than that of the full spectrum pore.

Furthermore, based on $T_{2}$ distribution curves under both $S_{w}$ and $S_{\text {ir }}$ depicted in Figure 11, adsorption and seepage pores can be distinguished by a $T_{2}$ cutoff $\left(T_{2 c}\right)[38,44] . T_{2 c}$ is a characteristic relaxation time which can divide adsorption pores and seepage pores. The pores with relaxation time shorter than $T_{2 c}\left(T_{2}<T_{2 c}\right)$ correspond to adsorption pores whereas the pores with relaxation time longer than $T_{2 c}\left(T_{2}>T_{2 c}\right)$ correspond to seepage pores. Parameters related to the division of adsorption pore and seepage pore, including $T_{2}$ cutoff $\left(T_{2 c}\right)$, free-fluid volume index (FFI), and bound fluid volume index (BVI), were calculated based on NMR measurements both at $S_{w}$ and $S_{\mathrm{ir}}$ conditions according to the calculation methods described in previous works $[38,44]$. As listed in Table 5, the $T_{2 c}$ values of all the investigated rock samples range from 1.55 to $20.03 \mathrm{~ms}$. Except for one fine-grained sandstone sample NT-S which has a relatively high value of $20.03 \mathrm{~ms}$, all other samples are less than $5 \mathrm{~ms}$ with a median value of $2.68 \mathrm{~ms}$. By comparison, these values are found to be significantly lower than those of other conventional reservoir rocks such as sandstones (standard $T_{2 c}=33 \mathrm{~ms}$ ) and carbonates (standard $T_{2 c}=92 \mathrm{~ms}$ ) $[43,57]$. It is already well understood that different types of rocks have varied $T_{2 c}$ values originated from their differences in many aspects such as pore types, pore structures, and mineral compositions which also have close and complex interconnections among them [43]. In this study, such a difference in $T_{2 c}$ values between our investigated mudrock and fine-grained sandstone samples and other conventional reservoir rock types may primarily attributed to their different lithologies and high contents of clay minerals in our investigated samples. According to the findings of Straley et al. [57], clay-bound water can be estimated from the $T_{2}$ distributions using a $T_{2}$ cutoff of $3 \mathrm{~ms}$ $\left(T_{2 c}=3 \mathrm{~ms}\right)$ in sandstones which coincide with our results.

In addition, it is found that, for the mudrock samples in this study, their values of FFI are relatively low and range from 7.93 to $13.61 \%$ whereas their BVI values are high and 


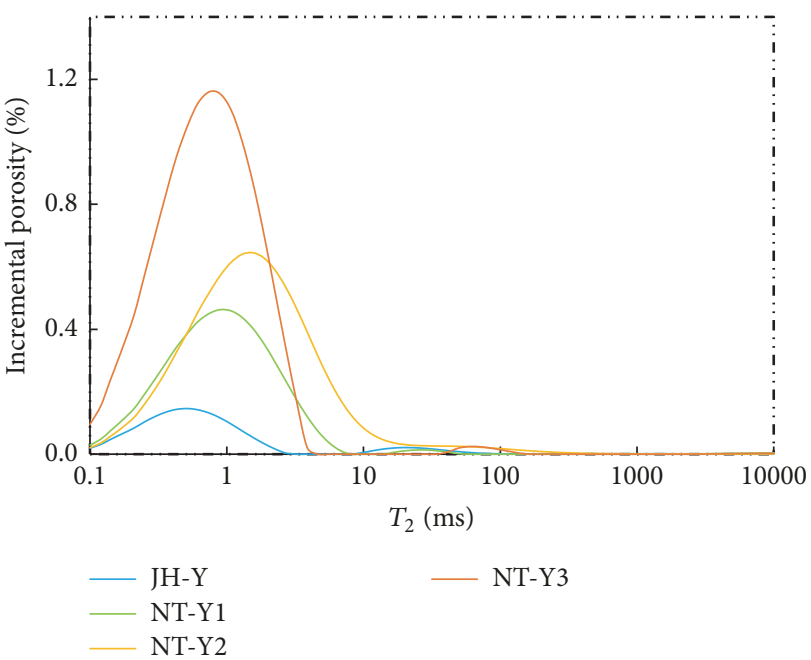

(a) Shale

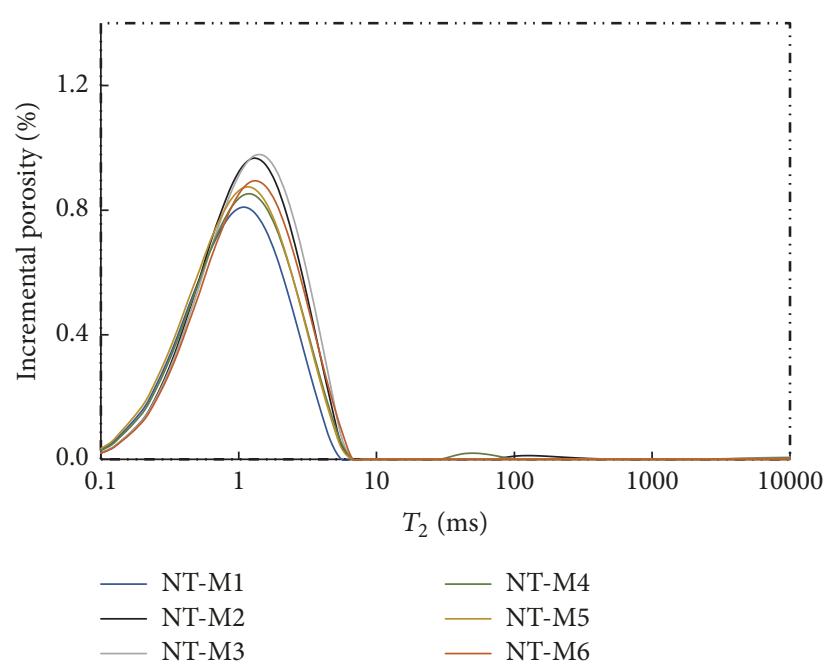

(b) Mudstone

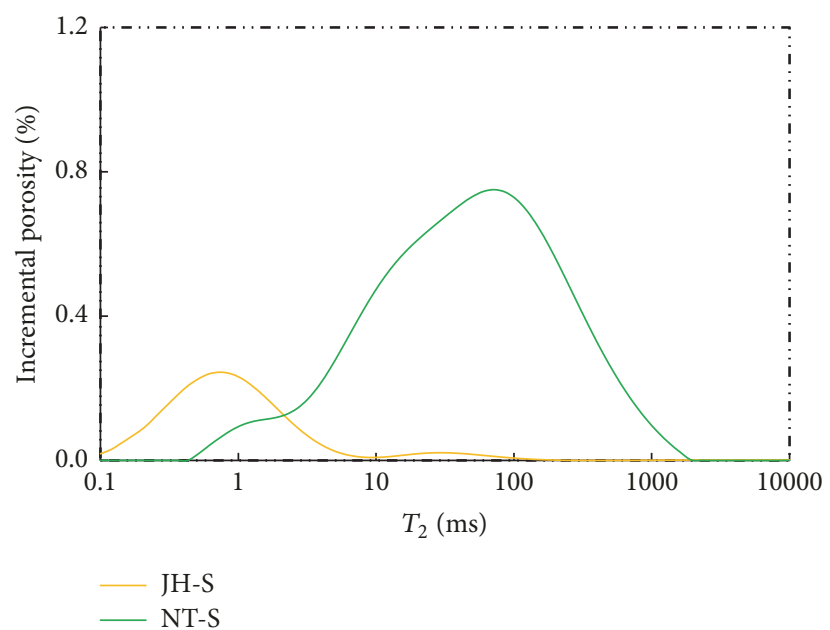

(c) Sandstone

FIGURE 8: $T_{2}$ spectra of the NMR measurements under the full water-saturated $\left(S_{w}\right)$ condition for the investigated samples.

TABLE 5: Pore-structure parameters measured by NMR.

\begin{tabular}{lcccc}
\hline Sample number & $T_{2 c}(\mathrm{~ms})$ & FFI $(\%)$ & BVI (\%) & FFI/BVI \\
\hline JH-Y & 1.55 & 13.61 & 86.39 & 86.88 \\
JH-S & 2.68 & 13.12 & 91.19 & 0.16 \\
NT-Y1 & 2.68 & 8.81 & 86.87 & 0.15 \\
NT-Y2 & 4.64 & 13.13 & 86.71 & 0.15 \\
NT-Y3 & 1.55 & 13.29 & 92.07 & 0.15 \\
NT-M1 & 2.68 & 7.93 & 89.44 & 0.09 \\
NT-M2 & 2.68 & 10.56 & 91.66 & 0.12 \\
NT-M3 & 3.22 & 8.34 & 91.35 & 0.09 \\
NT-M4 & 2.68 & 8.65 & 87.56 & 0.09 \\
NT-M5 & 2.23 & 12.44 & 88.41 \\
NT-M6 & 2.68 & 11.59 & 31.59 \\
NT-S & 20.03 & 68.41 & 0.14 \\
\hline
\end{tabular}


range from 86.39 to $92.07 \%$. Consequently their values of FFI/BVI were all lower than 0.16 . This is just the contrary for the sandstone sample NT-S which has a high FFI of $68.41 \%$ and correspondingly a high FFI/BVI of 2.17. It is thus inferred that adsorption pore is the only dominant pore type for all the mudrock samples and one tight sandstone sample JH-S investigated in this study, whereas for sandstone sample NT$S$ with relatively high porosity, seepage pore is the prominent pore type. In addition, correlation analyses showed that there is a positive correlation relationship between clay content and BVI whereas there is a negative correlation between clay content and FFI for our investigated samples. It further indicates that clay is a very important factor that determines the movability of the fluid in the pores of our samples due to its strong bonding effect on water.

\section{Discussion}

\subsection{Comparison of PSD Curves Determined by MIP and NMR}

4.1.1. Calibration Methods. NMR $T_{2}$ spectra can be quantitatively transformed into NMR PSD curves by comparing them to MIP PSD curves as described in many earlier works [35, $44,58]$. Based on NMR principles, the transverse relaxation time $\left(T_{2}\right)$ is a function of the surface to volume ratio of pores $(S / V)$ which can be expressed by $(1)[44,58]$, in which $\rho_{2}$ is a constant representing the transverse relaxation strength [38] (or the transverse surface relaxivity [58]). If the pore is assumed to be a cylinder with a radius of $r$, (1) can be transformed into (2) from which (3) then can be derived. Because each type of rock corresponds to a constant $\rho_{2}$, NMR PSD curves can be reconstructed according to (3) as long as the $\rho_{2}$ value is obtained.

$$
\begin{aligned}
\frac{1}{T_{2}} & =\rho_{2} \frac{S}{V} \\
\frac{1}{T_{2}} & =\rho_{2} \frac{S}{V}=\rho_{2} \frac{2}{r} \\
r & =2 \rho_{2} T_{2} .
\end{aligned}
$$

Next, the determination of $\rho_{2}$ is summarized into the following two methods based on theoretical models and calibration ideas employed in the previous works of Kleinberg and Yao et al. $[38,58]$ :

(1) Product of $T_{2}$ and $P_{c}$ method ( $T_{2} P_{c}$ method): the $\rho_{2}$ of the model of cylindrical tubes (see (2)) which is the base of the MIP and NMR measurements can be calculated using (4). The derivation of (4) is based on (2) and the Washburn equation (see (5)) which relates mercury injection pressures $\left(P_{c}\right)$ with radii of pores $(r)$ [59]. Because the contact angle $(\theta)$ between mercury and pore surface is $140^{\circ}$ and the surface tension of mercury $(\sigma)$ is $7.03 \times 10^{-3} \mathrm{psi} \cdot \mathrm{cm}$, (4) can be simplified to (6). Therefore, as long as the value of $T_{2} P_{c}$ is determined, $\rho_{2}$ can finally be calculated by

$$
\rho_{2}=\frac{(-\sigma \cos \theta)}{T_{2} P}
$$

$$
\begin{aligned}
r & =\frac{(-2 \sigma \cos \theta)}{P_{c}} \\
\rho_{2} & =\frac{\sigma \cos \theta}{T_{2} P_{c}}=\frac{53.85}{T_{2} P_{c}}
\end{aligned}
$$

(2) Weighted Arithmetic Mean method (WAM method): (2) can also be used to derive (7). Based on the PSD data of MIP, $r_{\text {wam }}$ (the weighted arithmetic mean of $r$ ) can be calculated. Meanwhile, $T_{2 \text { wam }}$ (the weighted arithmetic mean of $T_{2}$ ) can also be calculated based on the NMR $T_{2}$ distribution data. The transverse surface relaxivity $\rho_{2}$ can finally be calculated by substituting $r_{\text {wam }}$ and $T_{2 \text { wam }}$ values into (8).

$$
\begin{aligned}
& \rho_{2}=\frac{r}{2 T_{2}} \\
& \rho_{2}=\frac{r_{\text {wam }}}{2 T_{2 \mathrm{wam}}} .
\end{aligned}
$$

4.1.2. Calibration Results. The values of $\rho_{2}$ for our investigated samples were calculated, respectively, using the $T_{2} P_{c}$ and WAM methods and the results are listed in Table 6. The ratio of $\rho_{2}{ }^{*}$ from the $T_{2} P_{c}$ method to $\rho_{2}{ }^{* *}$ from the WAM method $\left(\rho_{2}{ }^{*} / \rho_{2}{ }^{* *}\right)$ indicates that the transverse surface relaxivity values determined by the $T_{2} P_{c}$ and WAM methods generally agree well with each other except for one sample NT-Y1. The exception of NT-Y1 may primarily owe to the high heterogeneity commonly existing in the natural rocks. Based on the calculated $\rho_{2}$ values, NMR $T_{2}$ spectra were able to be reconstructed and transformed into NMR PSD curves. NMR PSD curves calibrated with the $T_{2} P_{c}$ and WAM methods were further compared with those of MIP to verify the calibration results (see Appendix B). Comparisons of NMR PSD curves of three representative shale, mudstone, and fine-grained sandstone samples calibrated by the $T_{2} P_{c}$ (green line) and WAM (blue line) methods with MIP PSD curves (red line) are presented in Figure 9. It is observed that the main peaks of the PSD curves of NMR and MIP for the three types of rock samples coincide very well. Overall, good agreements between NMR and MIP PSD curves have been achieved with the help of the two calibration methods.

4.2. Permeability Estimation Based on NMR Measurements. Based on NMR measurements, a few kinds of permeability estimation models have been proposed and further developed by a lot of previous researchers in the past few decades $[38,40,43,44,57]$. Among them, the mean $T_{2}$ model (also called the SDR model) which is based on the SchlumbergerDoll-Research (SDR) equation $[43,60]$ and the free-fluid model (also called the Timur-Coates model) which is based on the Timur-Coates (TC) equation $[40,44]$ are commonly used to estimate permeability of conventional reservoir rocks such as sandstone and carbonate $[57,58]$. In the following, the applicabilities of the two typical models for permeability estimation from NMR data to mudrock samples are discussed. 
TABLE 6: Parameters derived from the methodsof $T_{2} P_{c}$ and WAM.

\begin{tabular}{|c|c|c|c|c|c|c|}
\hline \multirow{2}{*}{ Sample number } & \multicolumn{2}{|c|}{$T_{2} P_{c}$ method } & \multicolumn{3}{|c|}{ WAM method } & \multirow{2}{*}{$\rho_{2}{ }^{*} / \rho_{2}{ }^{* *}$} \\
\hline & $\rho_{2}{ }^{*}(\mu \mathrm{m} / \mathrm{s})$ & $T_{2} P_{c}(\mathrm{~s} \cdot \mathrm{psi})$ & $\rho_{2}{ }^{* *}(\mu \mathrm{m} / \mathrm{s})$ & $r_{\text {wam }}(\mathrm{nm})$ & $T_{2 \mathrm{wam}}(\mathrm{ms})$ & \\
\hline JH-Y & 8.98 & 6.00 & 7.82 & 10.30 & 0.66 & 1.15 \\
\hline JH-S & 4.49 & 12.00 & 4.39 & 99.10 & 11.29 & 1.02 \\
\hline NT-Y1 & 7.69 & 7.00 & 4.58 & 221.31 & 24.17 & 1.68 \\
\hline NT-Y2 & 6.73 & 8.00 & 6.61 & 26.96 & 2.04 & 1.02 \\
\hline NT-Y3 & 5.39 & 10.00 & 4.45 & 8.10 & 0.91 & 1.21 \\
\hline NT-M1 & 4.14 & 13.00 & 4.58 & 11.05 & 1.21 & 0.90 \\
\hline NT-M2 & 4.14 & 13.00 & 4.22 & 12.12 & 1.43 & 0.98 \\
\hline NT-M3 & 5.39 & 10.00 & 5.64 & 17.04 & 1.51 & 0.96 \\
\hline NT-M4 & 4.49 & 12.00 & 4.42 & 11.95 & 1.35 & 1.02 \\
\hline NT-M5 & 5.39 & 10.00 & 5.68 & 14.85 & 1.31 & 0.95 \\
\hline NT-M6 & 4.49 & 12.00 & 4.40 & 13.00 & 1.48 & 1.02 \\
\hline NT-S & 8.98 & 6.00 & 10.46 & 2512.62 & 120.15 & 0.86 \\
\hline
\end{tabular}

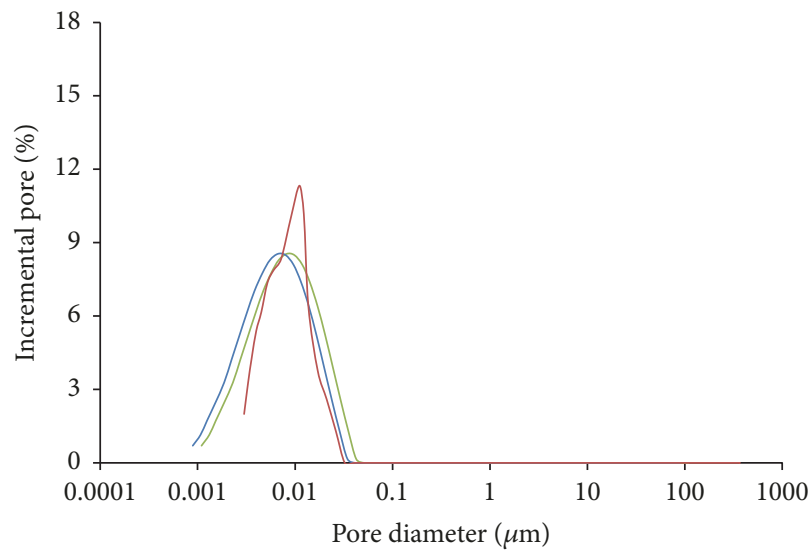

(a) Shale (NT-Y3)

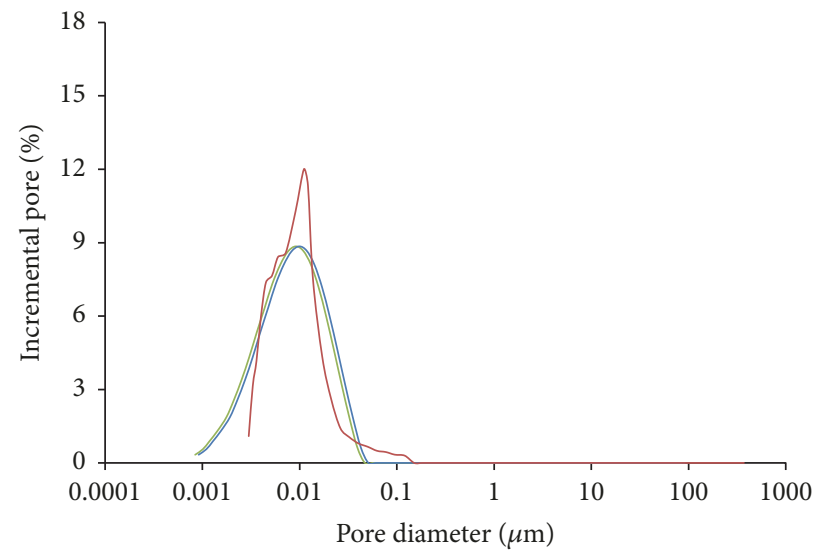

(b) Mudstone (NT-M1)

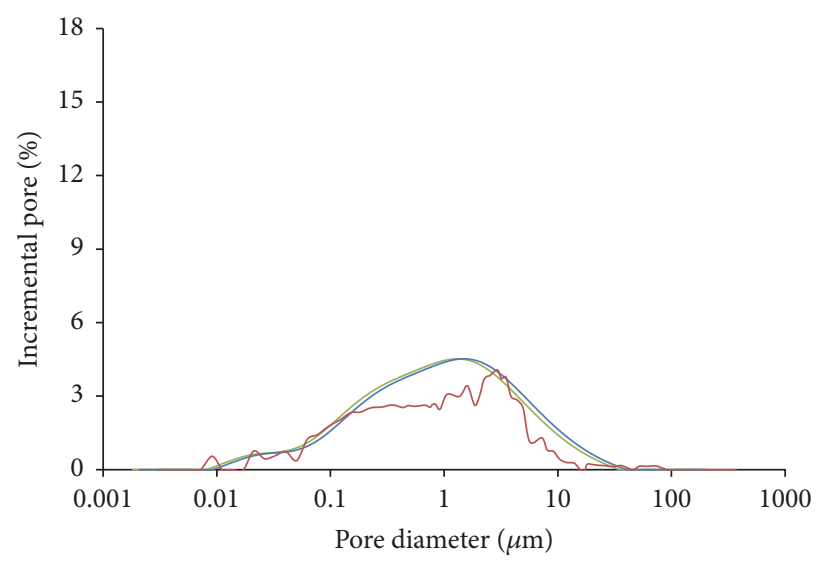

(c) Sandstone (NT-S)

FIGURE 9: Comparisons of NMR PSD curves of typical shale, mudstone, and fine-grained sandstone samples calibrated by the $T_{2} P_{c}($ green line) and weighted arithmetic mean (WAM) (blue line) methods with MIP PSD curves (red line).

4.2.1. The Mean $T_{2}$ Model (SDR). The mean $T_{2}$ model (or the SDR model) was usually described by the following equation $[38,44]$ :

$$
K_{\mathrm{SDR}}=C_{m} \varphi_{\mathrm{NMR}}{ }^{4} \times T_{2 \mathrm{gm}}^{2}
$$

where $K_{\mathrm{SDR}}(\mathrm{mD})$ is the estimated NMR permeability by the mean $T_{2}$ model; $T_{2 \mathrm{gm}}$ (ms) is the geometric mean of the $T_{2}$ distribution at saturated water condition $\left(S_{w}=100 \%\right)$; $\varphi_{\mathrm{NMR}}$ is the NMR porosity; $C_{m}$ is a constant related to the characteristic rock or formation type. The model is based on 
TABLE 7: Calculated MIP permeability $\left(K_{\text {MIP }}\right)$ and other related parameters in (11).

\begin{tabular}{lccccccc}
\hline Sample number & $K_{\text {MIP }}(\mathrm{mD})$ & $P_{t}(\mathrm{psia})$ & $L_{c}(\mu \mathrm{m})$ & $L_{\max }(\mu \mathrm{m})$ & $S_{(L \max )}$ & $V_{L \max }(\mathrm{mL} / \mathrm{g})$ & $V_{\text {tot }}(\mathrm{mL} / \mathrm{g})$ \\
\hline JH-Y & $2.539 \mathrm{E}-06$ & 34989.660 & 0.005 & 0.004 & 0.986 & 0.007 & 0.007 \\
JH-S & $4.732 \mathrm{E}-03$ & 796.640 & 0.227 & 0.183 & 0.530 & 0.006 & 0.020 \\
NT-Y1 & $3.708 \mathrm{E}-05$ & 14766.470 & 0.012 & 0.009 & 0.868 & 0.029 \\
NT-Y2 & $1.161 \mathrm{E}-04$ & 10568.400 & 0.017 & 0.014 & 0.820 & 0.023 \\
NT-Y3 & $3.672 \mathrm{E}-05$ & 16367.530 & 0.011 & 0.009 & 0.635 & 0.020 \\
NT-M1 & $4.870 \mathrm{E}-05$ & 16365.930 & 0.011 & 0.009 & 0.622 & 0.018 & 0.032 \\
NT-M2 & $4.201 \mathrm{E}-05$ & 14761.620 & 0.012 & 0.009 & 0.827 & 0.025 \\
NT-M3 & $6.231 \mathrm{E}-05$ & 14762.690 & 0.012 & 0.009 & 0.882 & 0.038 & 0.030 \\
NT-M4 & $3.629 \mathrm{E}-05$ & 14766.570 & 0.012 & 0.009 & 0.717 & 0.022 & 0.043 \\
NT-M5 & $4.521 \mathrm{E}-05$ & 14766.020 & 0.012 & 0.009 & 0.809 & 0.027 & 0.030 \\
NT-M6 & $4.564 \mathrm{E}-05$ & 14762.650 & 0.012 & 0.009 & 0.764 & 0.028 & 0.034 \\
NT-S & $2.126 \mathrm{E}+00$ & 61.520 & 2.940 & 2.213 & 0.336 & 0.023 & 0.069 \\
\hline
\end{tabular}

the geometric mean of the $T_{2}\left(T_{2 \mathrm{gm}}\right)$ and is free from the influence of the irreducible-water model. But it is sensitive to the nature of the fluid in the pores [43].

In fact, the SDR model expressed in (9) was based on a linear correlation relationship between permeability $K_{\mathrm{SDR}}$ and $\varphi^{4} T_{2 \mathrm{gm}}^{2}$. Therefore, the validation of the applicability of SDR model to our investigated mudrock samples can be validated through the correlation analysis between the measured $K_{g}$ and $\varphi^{4} T_{2 \mathrm{gm}}^{2}$. However, the results have shown that they were two uncorrelated variables and thus it is suggested that the SDR model is not appropriate for the low permeability mudrock samples investigated in this study.

4.2.2. The Free-Fluid Model (Timur-Coates). The simplified free-fluid model (or the Timur-Coates model) was expressed as follows $[40,44]$ :

$$
K_{\mathrm{TC}}=\left(\frac{\varphi_{\mathrm{NMR}}}{C_{c}}\right)^{4} \times\left(\frac{\mathrm{FFI}}{\mathrm{BVI}}\right)^{2},
$$

where $K_{\mathrm{TC}}(\mathrm{mD})$ is the calculated permeability by the TimurCoates model; $\varphi_{\mathrm{NMR}}$ is the NMR porosity; $C_{c}$ is a constant related to the rock type; FFI (\%) is the free-fluid index; BVI (\%) is the bound fluid index. As discussed in Section 3.5.2, the FFI and BVI are defined by the $T_{2}$ cutoff. In previous studies, different values were assigned to the empirical coefficient $C_{c}$ based on particular properties of certain kinds of rock or formation. For example, an experiential value of 6.2 is commonly given for sandstone formation [44]. However, as far as we know no empirical $C_{c}$ has yet been endowed for mudrocks. And the applicability of this model remains unknown.

Similar to the SDR model, the Timur-Coates model was established on a linear relationship between $\varphi_{\mathrm{NMR}} \sqrt{\mathrm{FFI} / \mathrm{BVI}}$ and $\sqrt[4]{K_{\mathrm{TC}}}$. In the same way, the applicability of the TimurCoates model to our investigated mudrock samples can also be validated by analyzing the correlation relationship between the two variable groups. But it is regrettable to find that there is still no valid linear relationship between them. Therefore it is demonstrated that the Timur-Coates model, like the SDR model, is not suitable for the investigated mudrock samples.

Finally, based on the above analyses, it can be concluded that the applicability of the two typical NMR permeability models proposed by the previous researchers, namely, the SDR and Timur-Coates models, is both very poor for the investigated mudrock samples.

\subsection{Permeability Estimation Based on MIP Measurements}

4.3.1. The Katz and Thompson (KT) Model. Permeability calculation based on mercury injection pressure data is also an alternative method for direct determination of permeability through experiments. The following equation introduced by Katz and Thompson $[1,5,6,61]$ can be employed to calculate the permeabilities of our investigated mudrock and finegrained sandstone samples using MIP data:

$$
K_{\mathrm{MIP}}=\frac{1}{89}\left(L_{\max }\right)^{2}\left(\frac{L_{\max }}{L_{c}}\right) \varphi_{\mathrm{MIP}} S_{(L \max )},
$$

where $K_{\mathrm{MIP}}$ (darcy, D) is the calculated MIP permeability; $L_{\max }(\mu \mathrm{m})$ is the pore-throat diameter at which hydraulic conductance is the maximum; $L_{c}(\mu \mathrm{m})$ is the characteristic length which is the pore-throat diameter corresponding to the threshold pressure $P_{t}$ (psia); $\varphi_{\text {MIP }}$ is the MIP porosity; $S_{(L \max )}$ represents the fraction of connected pore space at pore width of $L_{\max }$ which is calculated as $\left(V_{L \max }\right) /\left(V_{\text {tot }}\right)$ (the ratio of the cumulative pore volume at pore width of $L_{\max }$ $\left(V_{L \max }\right)$ to the total pore volume $\left.\left(V_{\text {tot }}\right)\right)$. The detailed steps of determining each parameter in (11) can refer to the work of $\mathrm{Gao}$ and $\mathrm{Hu}$ [6]. The calculated MIP permeability $\left(K_{\mathrm{MIP}}\right)$ and other related parameters in (11) for all the investigated samples are listed in Table 7.

4.3.2. Comparison between $K_{\mathrm{MIP}}$ and $K_{g}$. The calculated MIP permeability $\left(K_{\mathrm{MIP}}\right)$ by the Katz and Thompson (KT) model was compared with the measured gas permeability $\left(K_{g}\right)$ in Figure 10. It is noted that, for the shale and mudstone samples, measured permeability $K_{g}$ is higher than the MIP permeability $K_{\mathrm{MIP}}$ about two orders of magnitude, while for the two sandstone samples, JH-S and NT-S, the degree of 


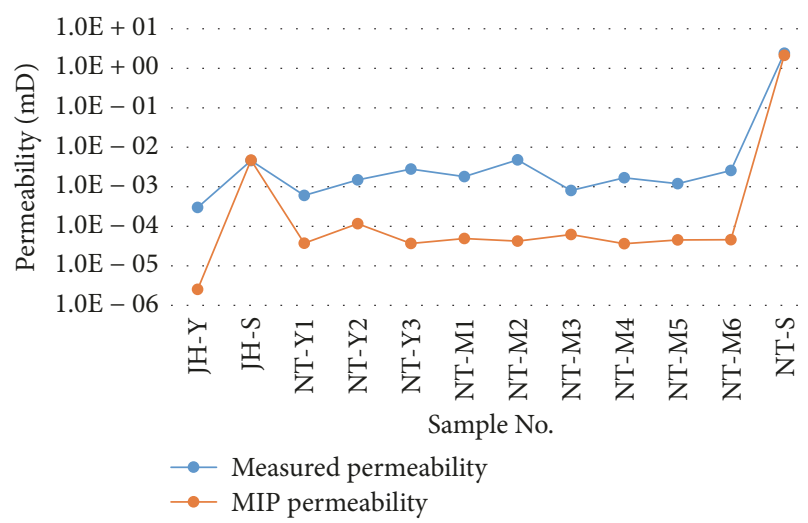

FIGURE 10: Comparison between the calculated MIP permeability $\left(K_{\text {MIP }}\right)$ and the measured gas permeability $\left(K_{g}\right)$.
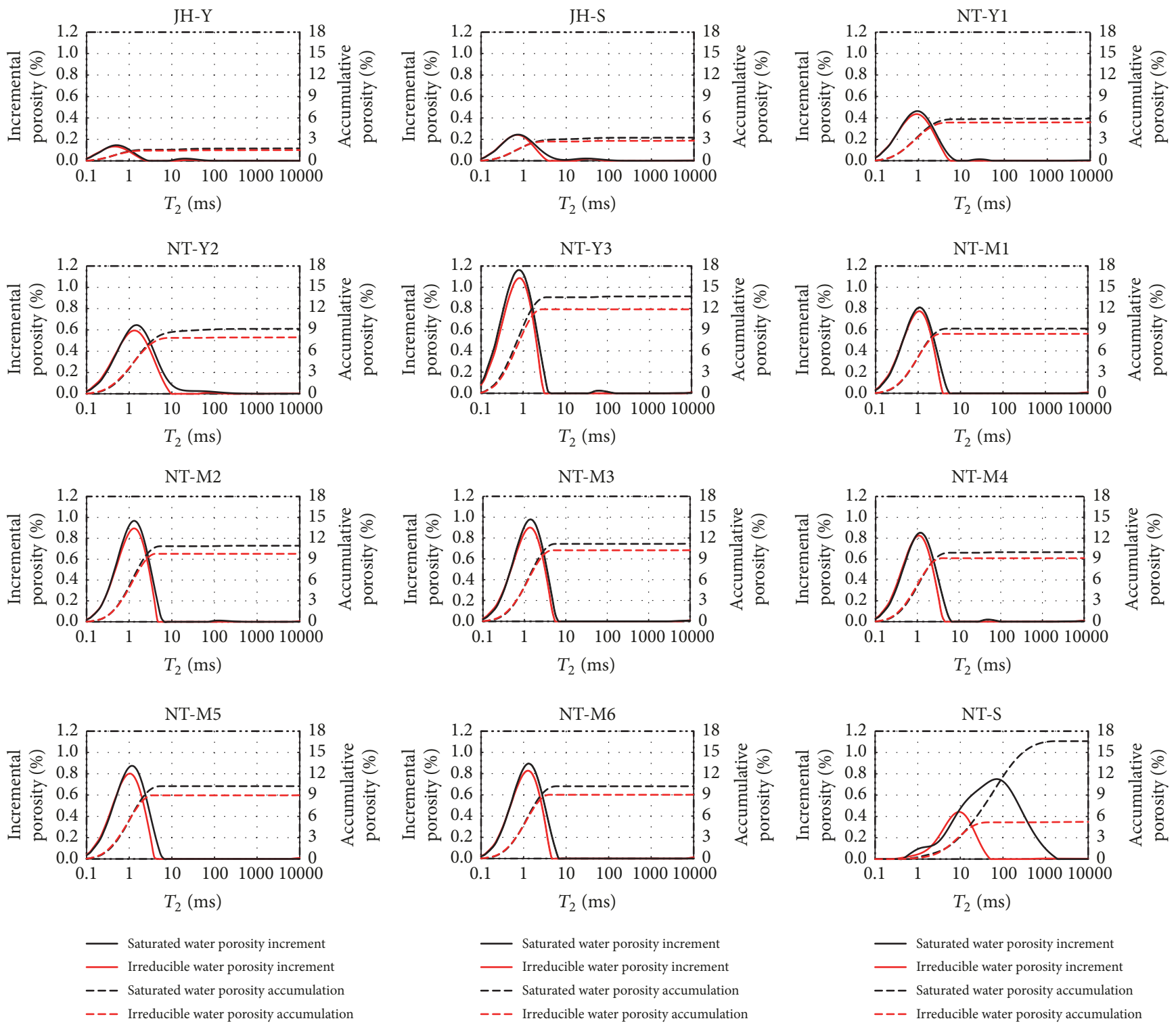

FIGURE 11: $T_{2}$ spectra of the NMR measurements under the full water-saturated $\left(S_{w}\right)$ condition (black line) and irreducible-water-saturated $\left(S_{\text {ir }}\right)$ condition (red line). 

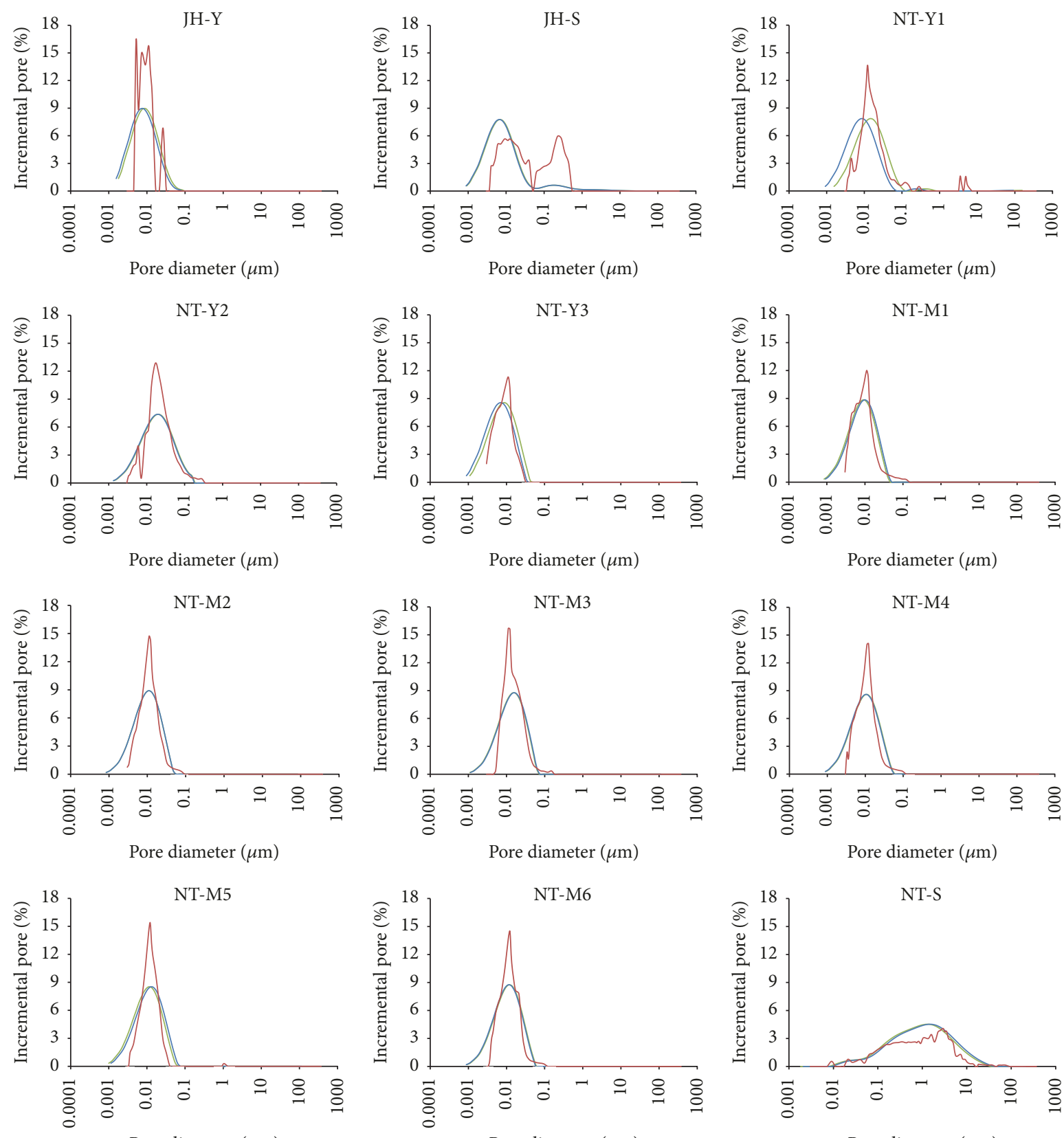

Pore diameter $(\mu \mathrm{m})$

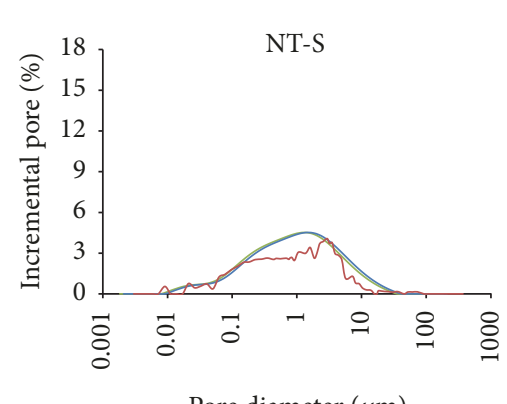

FIGURE 12: NMR PSD curves calibrated by the $T_{2} P_{c}$ (green line) and WAM (blue line) methods compared with MIP PSD curves (red line).

agreement between them is very good. It is thus inferred that the KT model is more suitable for the permeability prediction of sandstones rather than mudrocks.

\section{Conclusions}

In this study, multiple experimental approaches including FIB-SEM, MIP, and NMR have been used to obtain a comprehensive understanding of the pore structure characteristics of the mudrock and fine-grained sandstone samples collected from the coal bearing formations of two underground coal mines in China. Meanwhile, pore size distributions measured by MIP and NMR are compared and three classic permeability models based on measurements of MIP (the KT model) and NMR (the SDR and Timur-Coates models) are evaluated. Major results are as follows:

(1) FIB-SEM analyses indicate that the pore systems of the investigated samples are all relatively underdeveloped which correspond well with their relatively low porosities. Pore types of the selected mudrock and fine-grained sandstone samples observed by FIBSEM are mainly dominated by the mineral matrix pores with varied morphologies and very few organic matter pores were found.

(2) PSD curves of the mudrock samples measured by MIP basically present unimodal patterns and nanopores with diameter less than $0.1 \mu \mathrm{m}(d<0.1 \mu \mathrm{m})$ are the 
only predominant pore type for the mudrocks, whereas PSD curves of the fine-grained sandstone samples are featured by bimodal distributions. Meanwhile, the PSD patterns investigated by the NMR measurements generally agree well with those observed by MIP.

(3) Adsorption and seepage pores are distinguished based on $T_{2}$ distribution curves under both $S_{w}$ and $S_{\text {ir }}$ and it is found that, for all the mudrock samples and one tight sandstone sample JH-S with low porosity of $3.36 \%$, adsorption pore is their only dominant pore type, whereas for the sandstone sample NT-S with relatively high porosity of $16.50 \%$, seepage pore is the prominent pore type.

(4) PSD curves obtained by quantitatively calibrating the NMR $T_{2}$ spectra at $S_{w}$ using the $T_{2} P_{c}$ and WAM methods, respectively, generally agree well with the PSD curves determined by MIP. Thus, it is suggested that both the $T_{2} P_{c}$ and WAM methods are valid and can achieve good results for the scaling of NMR $T_{2}$ spectra of the investigated mudrock and fine-grained sandstone samples.

(5) The applicabilities of the two typical NMR permeability models, that is, the SDR and Timur-Coates models, are all very poor and cannot be used to estimate the permeabilities of the investigated mudrock samples on the basis of NMR data. Meanwhile, suitability evaluation of the Katz and Thompson (KT) model for permeability estimation from MIP data indicated that the KT model is not suitable for the permeability prediction of the investigated mudrock samples either but it can achieve good result of permeability estimation for the fine-grained sandstone samples. Thus, it is inferred that the classic permeability models which have been well feasible for conventional reservoir rocks such as sandstones may not be applicable to tight shale and mudstones which have more abundant clay contents as well as extremely fine and complicated pore structures.

\section{Appendix}

\section{A. NMR $T_{2}$ Spectra for All the Full Water-Saturated and Irreducible-Water-Saturated Samples}

See Figure 11.

\section{B. Comparison of the Calibrated NMR PSD Curves with MIP PSD Curves for All the Investigated Samples}

See Figure 12.

\author{
Abbreviations \\ XRD: X-ray diffraction \\ TOC: Total organic carbon
}

OM: $\quad$ Organic matter

FIB-SEM: Focused ion beam scanning electron microscopy

MIP: $\quad$ Mercury intrusion porosimetry

NMR: Nuclear magnetic resonance

PSD: $\quad$ Pore size distribution

WAM: Weighted arithmetic mean.

\section{Conflicts of Interest}

The authors declare that they have no conflicts of interest.

\section{Acknowledgments}

Funding for this study was provided by the National Natural Science Foundation of China (41502264; 41402273), the Yue Qi Outstanding Scholar Award Program of China University of Mining \& Technology (Beijing), the National Key Research and Development Program of China (2016YFC0600901), the Fundamental Research Funds for the Central Universities of China (2010QL07), and the Undergraduate Innovation Program of China University of Mining \& Technology, Beijing (C201706340).

\section{References}

[1] A. J. Katz and A. H. Thompson, "Quantitative prediction of permeability in porous rock," Physical Review B: Condensed Matter and Materials Physics, vol. 34, no. 11, pp. 8179-8181, 1986.

[2] M. Sahimi, "Flow phenomena in rocks: from continuum models to fractals, percolation, cellular automata, and simulated annealing," Reviews of Modern Physics, vol. 65, no. 4, pp. 1393$1534,1993$.

[3] Y. Wang, S. Liu, and D. Elsworth, "Laboratory investigations of gas flow behaviors in tight anthracite and evaluation of different pulse-decay methods on permeability estimation," International Journal of Coal Geology, vol. 149, pp. 118-128, 2015.

[4] T. Dong, N. B. Harris, K. Ayranci, C. E. Twemlow, and B. R. Nassichuk, "Porosity characteristics of the Devonian Horn River shale, Canada: Insights from lithofacies classification and shale composition," International Journal of Coal Geology, vol. 141-142, pp. 74-90, 2015.

[5] N. Zhang, M. He, B. Zhang, F. Qiao, H. Sheng, and Q. Hu, "Pore structure characteristics and permeability of deep sedimentary rocks determined by mercury intrusion porosimetry," Journal of Earth Science, vol. 27, no. 4, pp. 670-676, 2016.

[6] Z. Gao and Q. Hu, "Estimating permeability using median porethroat radius obtained from mercury intrusion porosimetry," Journal of Geophysics and Engineering, vol. 10, no. 2, Article ID 025014, 2013.

[7] D. Benavente, C. Pla, N. Cueto et al., "Predicting water permeability in sedimentary rocks from capillary imbibition and pore structure," Engineering Geology, vol. 195, pp. 301-311, 2015.

[8] W. D. Clelland, J. D. Kantorowicz, and T. W. Fens, "Quantitative analysis of pore structure and its effect on reservoir behaviour: Upper Jurassic Ribble Member sandstones, Fulmar Field, UK North Sea," Geological Society, London, Special Publications, vol. 69, pp. 57-79, 1992.

[9] I. Fatt, "Pore Volume Compressibilities of Sandstone Reservoir Rocks," Journal of Petroleum Technology, vol. 10, no. 03, pp. 6466, 2013. 
[10] A. Torabi, H. Fossen, and A. Braathen, "Insight into petrophysical properties of deformed sandstone reservoirs," AAPG Bulletin, vol. 97, no. 4, pp. 619-637, 2013.

[11] A. Escalona, "Petrophysical and seismic properties of lower Eocene clastic rocks in the central Maracaibo Basin," AAPG Bulletin, vol. 90, no. 4, pp. 679-696, 2006.

[12] T. Uchida, "Characteristics of pore-size distributions of sandstone reservoir rocks and their relationships to permeability," AAPG Bulletin, vol. 71, no. 5, pp. 623-623, 1987.

[13] F. J. Lucia, "Rock-fabric/petrophysical classification of carbonate pore space for reservoir characterization," The American Association of Petroleum Geologists Bulletin, vol. 79, no. 9, pp. 1275-1300, 1995.

[14] A. Lønøy, "Making sense of carbonate pore systems," $A A P G$ Bulletin, vol. 90, no. 9, pp. 1381-1405, 2006.

[15] J. C. Wendte and A. R. Gensamer, "Pore Systems in Jurassic Carbonate Reservoirs, United States Gulf Coast," AAPG Bulletin, vol. 63, no. 3, p. 551, 1979.

[16] Q. Wang, X. Chen, A. N. Jha, and H. Rogers, "Natural gas from shale formation - the evolution, evidences and challenges of shale gas revolution in United States," Renewable \& Sustainable Energy Reviews, vol. 30, pp. 1-28, 2014.

[17] P. H. Nelson, "Pore-throat sizes in sandstones, tight sandstones, and shales," AAPG Bulletin, vol. 93, no. 3, pp. 329-340, 2009.

[18] S. M. Swanson, M. D. Mastalerz, M. A. Engle et al., "Pore characteristics of Wilcox Group coal, U.S. Gulf Coast region: Implications for the occurrence of coalbed gas," International Journal of Coal Geology, vol. 139, no. 1, pp. 80-94, 2015.

[19] R. Yang, S. He, J. Yi, and Q. Hu, "Nano-scale pore structure and fractal dimension of organic-rich Wufeng-Longmaxi shale from Jiaoshiba area, Sichuan Basin: Investigations using FE-SEM, gas adsorption and helium pycnometry," Marine and Petroleum Geology, vol. 70, pp. 27-45, 2016.

[20] K. L. Milliken, M. Rudnicki, D. N. Awwiller, and T. Zhang, "Organic matter-hosted pore system, Marcellus Formation (Devonian), Pennsylvania,” AAPG Bulletin, vol. 97, no. 2, pp. 177-200, 2013.

[21] J. Klaver, G. Desbois, J. L. Urai, and R. Littke, “BIB-SEM study of the pore space morphology in early mature Posidonia Shale from the Hils area, Germany," International Journal of Coal Geology, vol. 103, pp. 12-25, 2012.

[22] R. M. Slatt and N. R. O'Brien, "Pore types in the Barnett and Woodford gas shales: contribution to understanding gas storage and migration pathways in fine-grained rocks," AAPG Bulletin, vol. 95, no. 12, pp. 2017-2030, 2011.

[23] R. G. Loucks, R. M. Reed, S. C. Ruppel, and D. M. Jarvie, "Morphology, genesis, and distribution of nanometer-scale pores in siliceous mudstones of the mississippian barnett shale," Journal of Sedimentary Research, vol. 79, no. 12, pp. 848-861, 2009.

[24] M. Sun, B. Yu, Q. Hu, S. Chen, W. Xia, and R. Ye, "Nanoscale pore characteristics of the Lower Cambrian Niutitang Formation Shale: A case study from Well Yuke \#1 in the Southeast of Chongqing, China," International Journal of Coal Geology, vol. 154-155, pp. 16-29, 2016.

[25] R. G. Loucks, R. M. Reed, S. C. Ruppel, and U. Hammes, “Spectrum of pore types and networks in mudrocks and a descriptive classification for matrix-related mudrock pores," AAPG Bulletin, vol. 96, no. 6, pp. 1071-1098, 2012.

[26] G. H. Grathoff, M. Peltz, F. Enzmann, and S. Kaufhold, "Porosity and permeability determination of organic-rich Posidonia shales based on 3-D analyses by FIB-SEM microscopy," Solid Earth, vol. 7, no. 4, pp. 1145-1156, 2016.

[27] S. Hemes, G. Desbois, J. L. Urai, B. Schröppel, and J.-O. Schwarz, "Multi-scale characterization of porosity in Boom Clay (HADES-level, Mol, Belgium) using a combination of Xray $\mu$-CT, $2 \mathrm{D}$ BIB-SEM and FIB-SEM tomography," Microporous and Mesoporous Materials, vol. 208, pp. 1-20, 2015.

[28] X. Gu, D. R. Cole, G. Rother, D. F. R. Mildner, and S. L. Brantley, "Pores in marcellus shale: A neutron scattering and FIB-SEM study," Energy \& Fuels, vol. 29, no. 3, pp. 1295-1308, 2015.

[29] G. Desbois, J. L. Urai, and P. A. Kukla, "Morphology of the pore space in claystones - Evidence from BIB/FIB ion beam sectioning and cryo-SEM observations," eEarth Discussions, vol. 4, no. 1, pp. 15-22, 2009.

[30] K. Jiao, S. Yao, C. Liu et al., "The characterization and quantitative analysis of nanopores in unconventional gas reservoirs utilizing FESEM-FIB and image processing: An example from the lower Silurian Longmaxi Shale, upper Yangtze region, China," International Journal of Coal Geology, vol. 128-129, pp. 1-11, 2014.

[31] S. Zhou, G. Yan, H. Xue, W. Guo, and X. Li, "2D and 3D nanopore characterization of gas shale in Longmaxi formation based on FIB-SEM," Marine and Petroleum Geology, vol. 73, pp. 174-180, 2016.

[32] H. Giesche, "Mercury porosimetry: a general (practical) overview," Particle \& Particle Systems Characterization, vol. 23, no. 1, pp. 9-19, 2006.

[33] C. L. Vavra, J. G. Kaldi, and R. M. Sneider, "Geological applications of capillary pressure: a review," The American Association of Petroleum Geologists Bulletin, vol. 76, no. 6, pp. 840-850, 1992.

[34] C. A. Léon y León, "New perspectives in mercury porosimetry," Advances in Colloid and Interface Science, vol. 76-77, pp. 341-372, 1998.

[35] M. Zou, C. Wei, M. Zhang, J. Shen, Y. Chen, and Y. Qi, "Classifying coal pores and estimating reservoir parameters by nuclear magnetic resonance and mercury intrusion porosimetry," Energy \& Fuels, vol. 27, no. 7, pp. 3699-3708, 2013.

[36] Y. Yao and D. Liu, "Comparison of low-field NMR and mercury intrusion porosimetry in characterizing pore size distributions of coals," Fuel, vol. 95, pp. 152-158, 2012.

[37] M. A. Hodgkins and J. J. Howards, "Application of NMR logging to reservoir characterization of low-resistivity sands in the Gulf of Mexico," AAPG Bulletin, vol. 83, no. 1, pp. 114-127, 1999.

[38] Y. Yao, D. Liu, Y. Che, D. Tang, S. Tang, and W. Huang, "Petrophysical characterization of coals by low-field nuclear magnetic resonance (NMR)," Fuel, vol. 89, no. 7, pp. 1371-1380, 2010.

[39] H. Pape, J. E. Tillich, and M. Holz, "Pore geometry of sandstone derived from pulsed field gradient NMR," Journal of Applied Geophysics, vol. 58, no. 3, pp. 232-252, 2006.

[40] A. Timur, "Pulsed Nuclear Magnetic Resonance Studies of Porosity, Movable Fluid, and Permeability of Sandstones," Journal of Petroleum Technology, vol. 21, no. 6, pp. 775-786, 1969.

[41] R. Yang, F. Hao, S. He et al., "Experimental investigations on the geometry and connectivity of pore space in organic-rich Wufeng and Longmaxi shales," Marine and Petroleum Geology, vol. 84, pp. 225-242, 2017.

[42] J. Lai and G. Wang, "Fractal analysis of tight gas sandstones using high-pressure mercury intrusion techniques," Journal of Natural Gas Science and Engineering, vol. 24, pp. 185-196, 2015.

[43] H. Westphal, I. Surholt, C. Kiesl, H. F. Thern, and T. Kruspe, "NMR measurements in carbonate rocks: Problems and an 
approach to a solution," Pure and Applied Geophysics, vol. 162, no. 3, pp. 549-570, 2005.

[44] G. R. Coates, L. Xiao, and M. G. Prammer, NMR Logging: Principles and Applications, vol. 234, Haliburton Energy Services, Houston, Tex, USA, 1999.

[45] S. Peng, Q. Hu, S. Dultz, and M. Zhang, "Using X-ray computed tomography in pore structure characterization for a Berea sandstone: Resolution effect," Journal of Hydrology, vol. 472-473, pp. 254-261, 2012.

[46] P. Spanne, J. F. Thovert, C. J. Jacquin, W. B. Lindquist, K. W. Jones, and P. M. Adler, "Synchrotron computed microtomography of porous media: Topology and transports," Physical Review Letters, vol. 73, no. 14, pp. 2001-2004, 1994.

[47] Y. Nakashima and S. Kamiya, "Mathematica programs for the analysis of three-dimensional pore connectivity and anisotropic tortuosity of porous rocks using X-ray computed tomography image data," Journal of Nuclear Science and Technology, vol. 44, no. 9, pp. 1233-1247, 2007.

[48] Y. B. Yao, D. M. Liu, Y. Che, D. Z. Tang, S. S. Tang, and W. H. Huang, "Non-destructive characterization of coal samples from China using microfocus X-ray computed tomography," International Journal of Coal Geology, vol. 80, no. 2, pp. 113-123, 2009.

[49] S. Mayo, M. Josh, Y. Nesterets et al., "Quantitative micro-porosity characterization using synchrotron micro-CT and xenon K-edge subtraction in sandstones, carbonates, shales and coal," Fuel, vol. 154, pp. 167-173, 2015.

[50] W. N. Yuan, Z. J. Pan, X. Li et al., "Experimental study and modelling of methane adsorption and diffusion in shale," Fuel, vol. 117, pp. 509-519, 2014.

[51] R. Yang, S. He, Q. Hu, M. Sun, D. Hu, and J. Yi, "Applying SANS technique to characterize nano-scale pore structure of Longmaxi shale, Sichuan Basin (China)," Fuel, vol. 197, pp. 9199, 2017.

[52] M. Sun, B. Yu, Q. Hu et al., "Pore characteristics of Longmaxi shale gas reservoir in the Northwest of Guizhou, China: Investigations using small-angle neutron scattering (SANS), helium pycnometry, and gas sorption isotherm," International Journal of Coal Geology, vol. 171, pp. 61-68, 2017.

[53] C. R. Clarkson, M. Freeman, L. He et al., "Characterization of tight gas reservoir pore structure using USANS/SANS and gas adsorption analysis," Fuel, vol. 95, pp. 371-385, 2012.

[54] S. M. Rimmer, J. A. Thompson, S. A. Goodnight, and T. L. Robl, "Multiple controls on the preservation of organic matter in Devonian-Mississippian marine black shales: Geochemical and petrographic evidence," Palaeogeography, Palaeoclimatology, Palaeoecology, vol. 215, no. 1-2, pp. 125-154, 2004.

[55] J. Zhao, Z. Jin, Z. Jin, Y. Geng, X. Wen, and C. Yan, “Applying sedimentary geochemical proxies for paleoenvironment interpretation of organic-rich shale deposition in the Sichuan Basin, China," International Journal of Coal Geology, vol. 163, pp. 52-71, 2016.

[56] E. D. Pittman, "Porosity, diagenesis and productive capability of sandstone reservoirs," SEPM Special Publication, vol. 26, pp. 159-173, 1979.

[57] C. Straley, D. Rossini, H. Vinegar, P. Tutunjian, and C. Morriss, "Core analysis by low-field NMR," Log Analyst, vol. 38, no. 2, pp. 84-93, 1997.

[58] R. L. Kleinberg, "Utility of NMR T2 distributions, connection with capillary pressure, clay effect, and determination of the surface relaxivity parameter $\rho 2$," Magnetic Resonance Imaging, vol. 14, no. 7-8, pp. 761-767, 1996.
[59] E. W. Washburn, "The dynamics of capillary flow," Physical Review A: Atomic, Molecular and Optical Physics, vol. 17, no. 3, pp. 273-283, 1921.

[60] W. E. Kenyon, P. I. Day, C. Straley, and J. F. Willemsen, “Threepart study of NMR longitudinal relaxation properties of watersaturated sandstones," SPE Formation Evaluation, vol. 3, no. 3, pp. 622-636, 1988.

[61] A. J. Katz and A. H. Thompson, "Prediction of rock electrical conductivity from mercury injection measurements." Journal of Geophysical Research: Atmospheres, vol. 92, no. 1, pp. 599-607, 1987. 

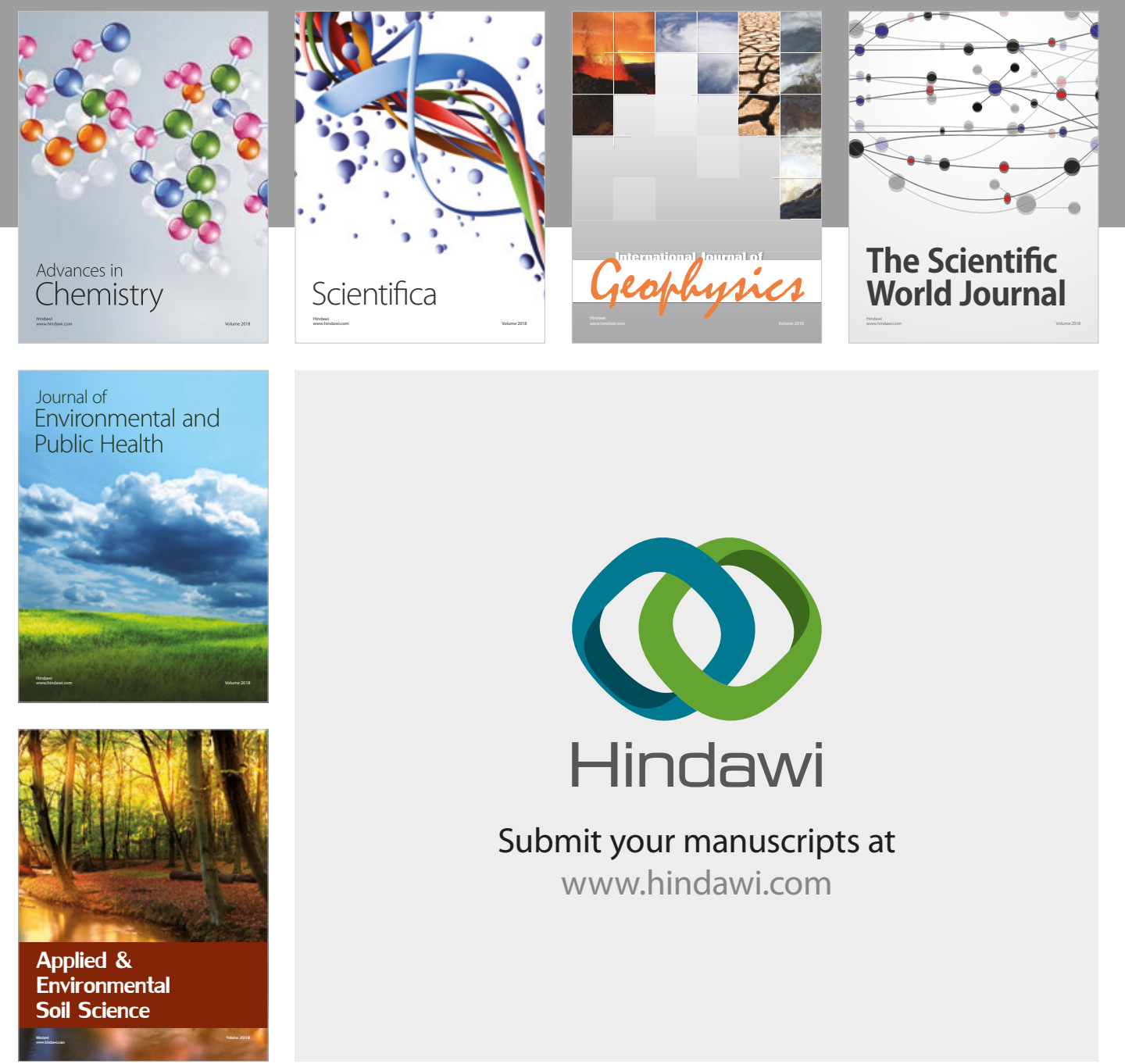

The Scientific

\section{World Journal}
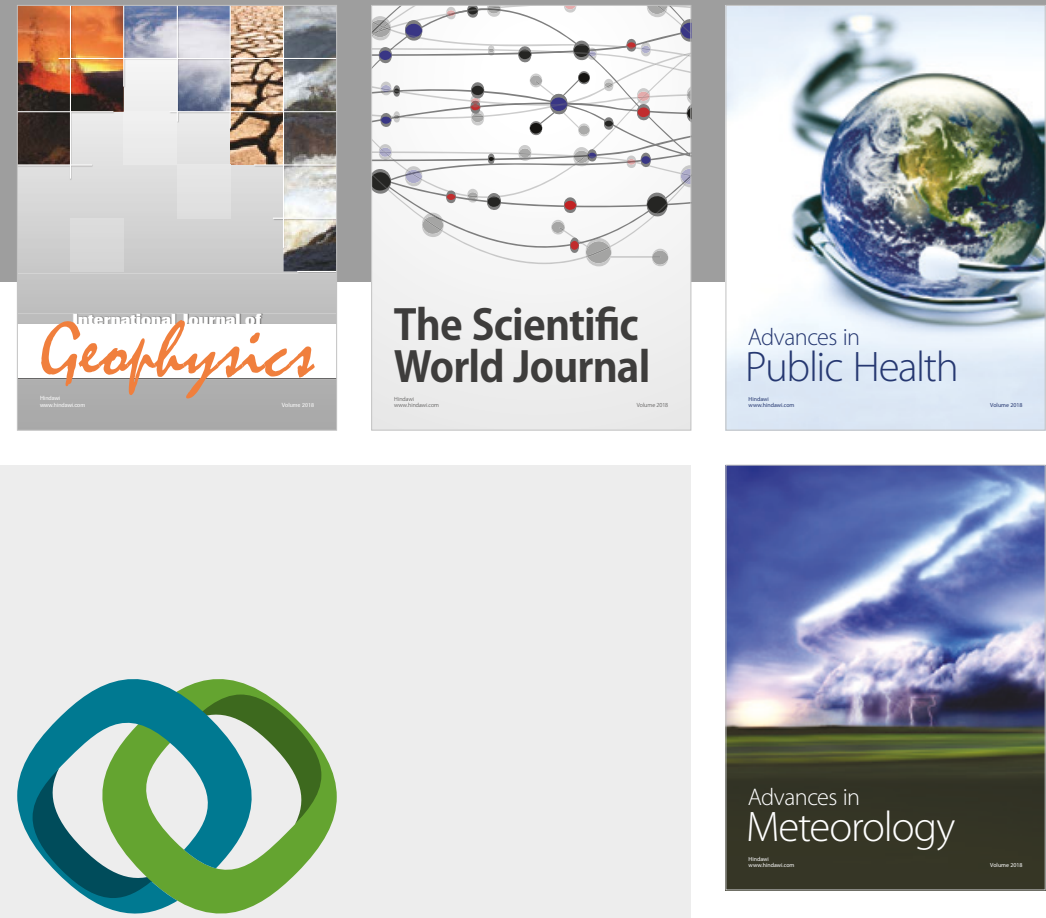

Advan

Public Health

\section{Hindawi}

Submit your manuscripts at

www.hindawi.com
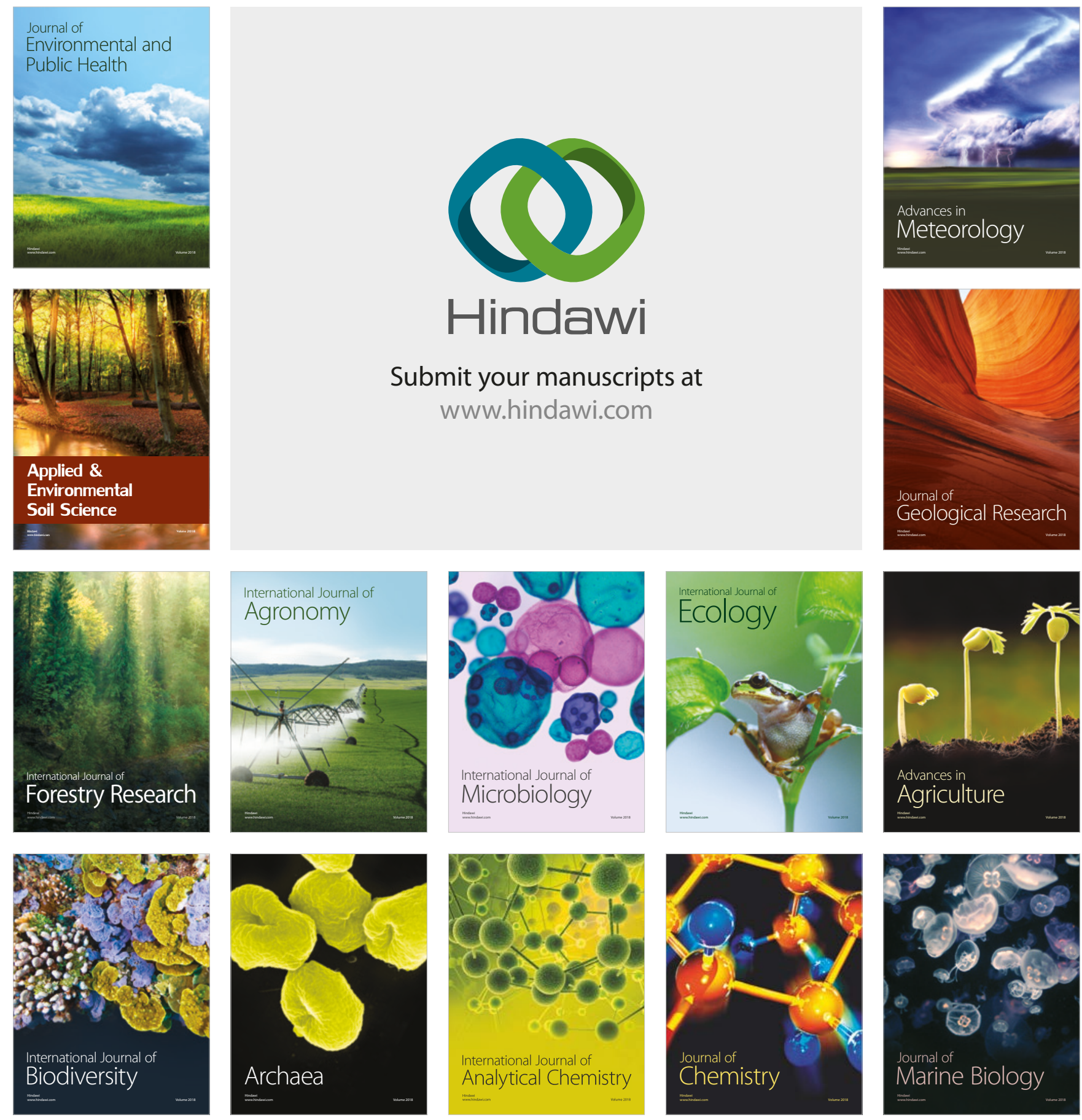